\title{
Capital Facilities Information Handover Guide, Part 1
}

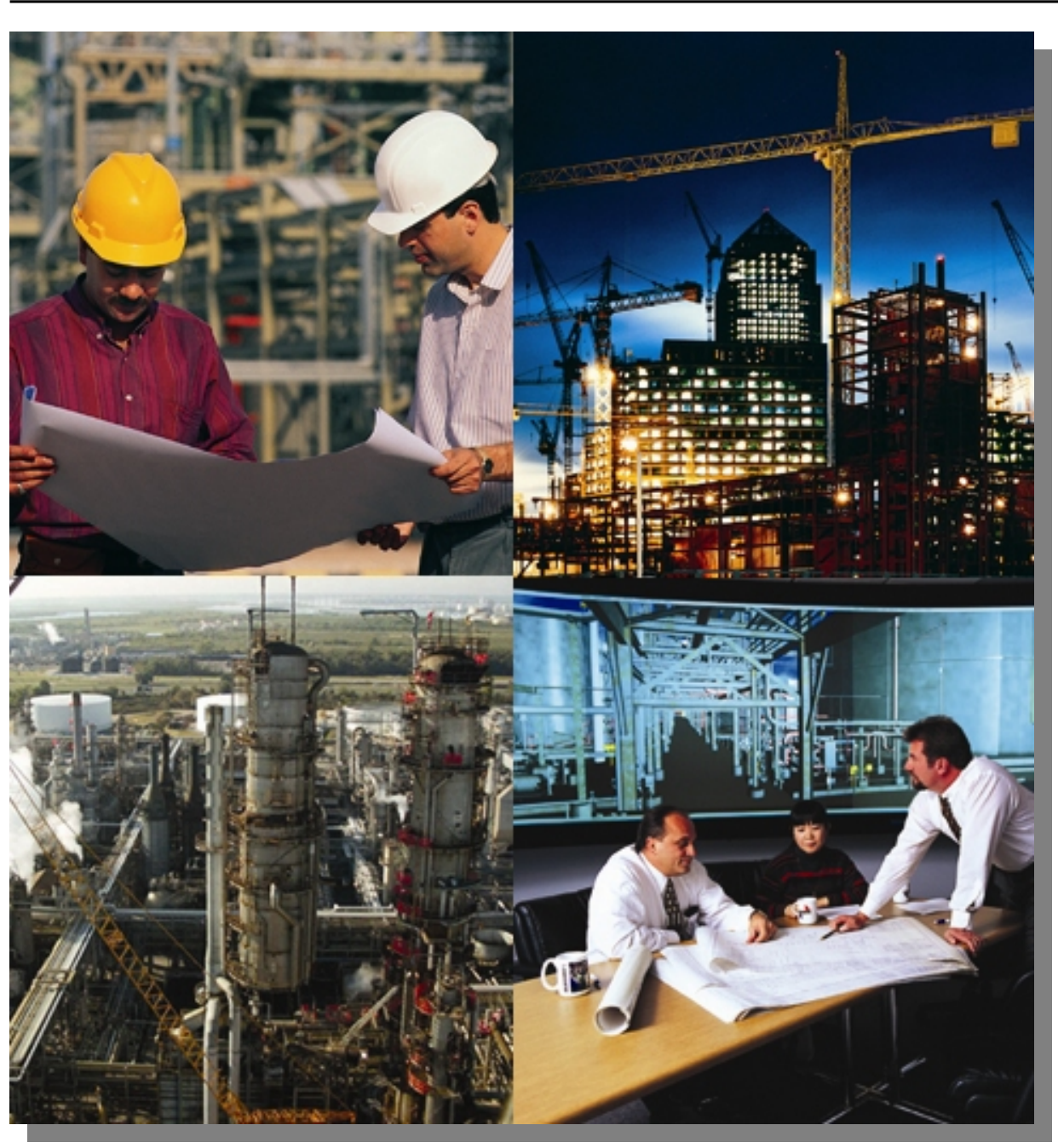

Project Leaders:

Kristine K. Fallon

Mark E. Palmer

In Cooperation with:

FIATECH and

USPI-NL

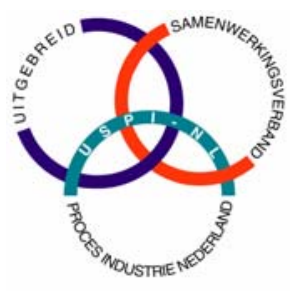

FIATECH

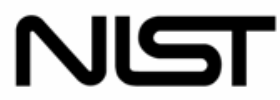

National Institute of Standards and Technology Technology Administration, U.S. Department of Commerce 


\title{
Capital Facilities Information Handover Guide, Part 1
}

\author{
Kristine K. Fallon \\ Kristine Fallon Associates, Inc.
}

Mark E. Palmer

Building and Fire Research Laboratory

NIST

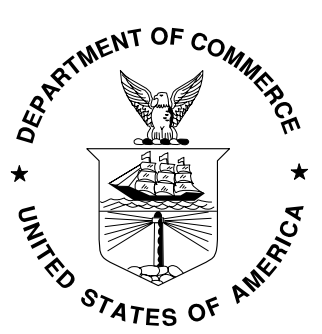

U.S. DEPARTMENT OF COMMERCE

Carlos M. Gutierrez, Secretary

TECHNOLOGY ADMINISTRATION

Michelle O'Neill, Acting Under Secretary of Commerce for Technology NATIONAL INSTITUTE OF STANDARDS AND TECHNOLOGY 


\section{Acknowledgements}

This document is the result of a number of organizations and individuals cooperating to improve the development, delivery and use of information for capital facilities projects. The following individuals contributed to this work:

David Adam, BP

Bob Batcheler, Newforma

Ian Bishop, Foster Wheeler

Robert Chapman, NIST

Alan Doniger, POSC

Paul van Exel, USPI-NL

Andy Fuhrman, OSCRE

Ian Glendinning, Intergraph

Ric Jackson, FIATECH

Judy Ludlow, Petro-Canada

Dale Osmond, AMEC Americas Limited

Onno Paap, Fluor

Steve Pearson, Pearson-Harper

Kent Reed, NIST

Andries van Renssen, Shell Global Solutions International B.V.

Mervyn Richards, MR1 Consulting Ltd.

Dalip Sud, Shell Global Solutions International B.V.

Tom Teague, ePlantData

Hans Teijgeler

Wolfgang Wilkes, Semaino Technologies GmbH 


\section{TABLE OF CONTENTS}

EXECUTIVE SUMMARY

1 INTRODUCTION 3

$\begin{array}{lll}1.1 & \text { Background } & 3\end{array}$

$\begin{array}{llr}1.2 & \text { Business Case for Change } & 4\end{array}$

$\begin{array}{lll}1.3 & \text { Realigning the Delivery Model } & 6\end{array}$

$\begin{array}{lll}1.4 & \text { Accelerating Technical Progress } & 7\end{array}$

$\begin{array}{lll}1.5 & \text { Capital Facilities Industry Roadmap } & 8\end{array}$

1.5.1 Internal Data Readiness 9

1.5.2 External Data Readiness $\quad 9$

1.6 Purpose of the Information Handover Guide 9

$\begin{array}{lll}1.7 & \text { Target Audiences } & 10\end{array}$

$1.8 \quad$ Organization and Scope of the Information Handover Guide 10

$\begin{array}{lll}1.9 & \text { Organization of Part } 1 & 11\end{array}$

2 THE HANDOVER PROCESS $\quad 12$

$\begin{array}{llr}2.1 & \text { Capital Facility Life Cycle } & 12\end{array}$

$\begin{array}{ll}2.1 .1 & 12\end{array}$

$\begin{array}{ll}2.1 .2 \text { Design } & 12 \\ 2.1 .3\end{array}$

$\begin{array}{ll}\text { 2.1.3 Construction } & 12\end{array}$

$\begin{array}{ll}\text { 2.1.4 Project Closeout / Commissioning } & 13\end{array}$

$\begin{array}{ll}2.1 .5 & 14\end{array}$

$\begin{array}{ll}2.1 .6 & 15 \\ 2.1 .7 & 15 \text { Disposal }\end{array}$

$\begin{array}{ll}\text { 2.1.7 Increasing Information Interdependence } & 15\end{array}$

2.2 Steps in Establishing the Handover Plan $\quad 15$

2.2.1 Facility Life Cycle Information Strategy 16

2.2.2 Handover Requirements 16

$\begin{array}{ll}\text { 2.2.3 Project Information Handover Plan } & 16\end{array}$

$\begin{array}{ll}2.2 .4 & \text { Implementation } \\ \end{array}$

$3 \quad$ FACILITY LIFE CYCLE INFORMATION STRATEGY 17

$\begin{array}{lll}\text { 3.1 Contents of the Facility Life Cycle Information Strategy } & 17\end{array}$

$\begin{array}{llr}3.2 & \text { Where to Begin } & 18\end{array}$

4 DETERMINE DETAILED HANDOVER REQUIREMENTS 20

$\begin{array}{llr}4.1 & \text { The Uses of Handover Information } & 20\end{array}$

\begin{tabular}{ll}
4.2 & Characteristics of Information Packages \\
\hline
\end{tabular} 


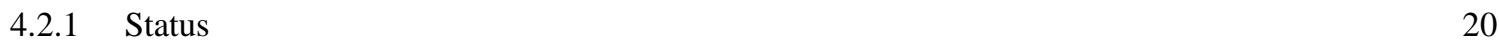

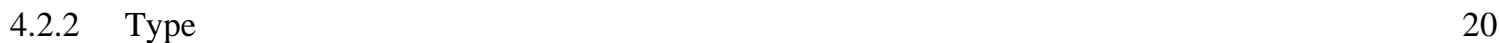

$\begin{array}{ll}4.2 .3 \text { Retention } & 21\end{array}$

4.3 Information Forms and Formats $\quad 21$

$\begin{array}{llr}4.3 .1 & \text { Overview } & 21\end{array}$

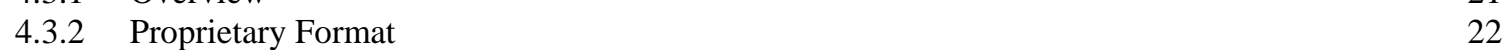

$\begin{array}{lr}\text { 4.3.3 Standard Format } & 22\end{array}$

$\begin{array}{ll}\text { 4.3.4 Structured Data } & 23\end{array}$

$\begin{array}{lr}\text { 4.3.5 Unstructured Data } & 23\end{array}$

$\begin{array}{llr}\text { 4.3.6 Hard Copy } & 23\end{array}$

$\begin{array}{ll}\text { 4.3.7 Considerations in Selecting Preferred Form and Format } & 23\end{array}$

$\begin{array}{ll}\text { 4.3.8 Costs and Benefits of Information Forms and Formats } & 24\end{array}$

$\begin{array}{ll}\text { 4.3.9 Format Specification } & 25\end{array}$

$\begin{array}{llr}4.4 & \text { Metadata } & 25\end{array}$

$\begin{array}{llr}\text { 4.5 When to Begin } & 26\end{array}$

$5 \quad$ THE PROJECT INFORMATION HANDOVER PLAN 27

$\begin{array}{llr}5.1 & \text { Overview } & 27\end{array}$

5.2 Developing the Project Information Handover Plan 27

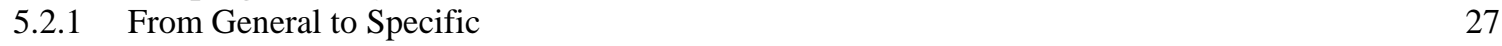

$\begin{array}{ll}\text { 5.2.2 Information Quality } & 27\end{array}$

$\begin{array}{llr}5.2 .3 & \text { Logistics } & 28\end{array}$

$\begin{array}{llr}5.3 & \text { Relationship to Facility Life Cycle Information Strategy } & 28\end{array}$

5.4 Handover Plan Contents $r$

$\begin{array}{ll}\text { 5.4.1 Information Packages } & 29\end{array}$

$\begin{array}{llr}5.4 .2 & \text { Handover Methods } & 29\end{array}$

\begin{tabular}{ll}
5.4 .3 & Responsibilities \\
\hline 5.4 .4 & Timing
\end{tabular}

$\begin{array}{llr}5.4 .4 & \text { Timing } & 30\end{array}$

$\begin{array}{lll}\text { 5.4.5 } & \text { Method of Transferring Data } & 30\end{array}$

$\begin{array}{ll}\text { 5.4.6 Information Quality Management } & 30\end{array}$

$\begin{array}{llr}5.5 & \text { Storing and Preserving Handover Information } & 31\end{array}$

6 IMPLEMENTING THE HANDOVER PROCESS 32

6.1 Technical Implementation $\quad 32$

$\begin{array}{ll}\text { 6.1.1 Structured Data in Standard Format } & 32\end{array}$

$\begin{array}{ll}6.1 .2 & \text { Technical Solutions } \\ 6.1 .3 & \text { Proprietary Formats }\end{array}$

$\begin{array}{lll}6.1 .3 & \text { Proprietary Formats } & 34\end{array}$

$\begin{array}{lll}6.1 .4 & \text { Electronic Images } & 34\end{array}$

$\begin{array}{ll}\text { 6.1.5 Hardcopy } & 35\end{array}$

$\begin{array}{llr}6.2 & \text { Project Procedures } & 35\end{array}$

$\begin{array}{llr}\text { 6.3 } & \text { Staff Training } & 35\end{array}$

$\begin{array}{llr}\text { 6.4 Compliance Checks } & 35\end{array}$

6.5 Continuous Improvement $\quad 35$ 
7 CONCLUSIONS AND RECOMMENDATIONS

8 APPENDICES $\quad 37$

$\begin{array}{lll}\text { 8.1 APPENDIX A - Glossary } & 37\end{array}$

8.2 APPENDIX B - Survey Forms 440

$\begin{array}{llr}\text { 8.2 APPENDIX C - Bibliography } & 81\end{array}$

8.3 APPENDIX D - Links to information delivery specifications and standards 83 


\section{Executive Summary}

All developed nations invest a substantial portion of their gross domestic product in capital facilities their planning, design, construction, operation, maintenance, renovation and decommissioning. There is increasing pressure on the global capital facilities industry to perform more efficiently. Since the late 1990s, a number of studies have addressed this issue and provided analyses and recommendations.

Three statements can summarize the challenges identified in these studies:

1. There is a lack of understanding on the part of industry participants of how to achieve integrated information and workflows through the application of information technology.

2. There are gaps in the availability of information technology tools and data standards to support integrated information and workflows throughout the facility life cycle.

3. Current industry structure and business practices, including procurement practices and regulatory, insurance and contractual requirements, present obstacles to integrated work and information flows.

The National Institute of Standards and Technology's (NIST) study, Cost Analysis of Inadequate Interoperability in the U.S. Capital Facilities Industry (referred to as NIST GCR 04-867), is of particular interest because it identifies and quantifies the efficiency losses in the U.S. capital facilities industry attributable to inadequate interoperability. Interoperability is defined as "the ability to manage and communicate electronic product and project data between collaborating firms and within individual companies' design, construction, maintenance, and business process systems” (NIST GCR 04-867, page ES-1). The researchers very conservatively estimated those losses to be $\$ 15.8$ billion in 2002. This figure excludes the losses for residential facilities and transportation infrastructure.

This Capital Facilities Information Handover Guide (CFIHG) is designed to address the first two challenges. Part 1 of the guide, presented here, defines a methodology for defining the information requirements for the full facility life cycle and then developing and implementing an information handover plan for a specific capital facility project. These are the major steps:

- Establish an overall facility life cycle information strategy. This strategy should be driven by business requirements and aligned with the relevant company information and security policies.

- Determine the business requirements for information to be handed over at each life cycle stage, including:

- What information is required

- How the information is to be used

- What are the requirements for updating and retaining the information

- What format is required for subsequent uses

- What metadata are required

- What quality of the information is needed

- Develop a handover plan, which forms part of the overall project information plan, to include:

- Information requirements (as defined above)

- Methods of information handover

- Detailed format specifications for each information type

- Timing

- Responsibilities for creating, delivering, receiving, validating, securing and maintaining the information

- Information quality management

- Implement the handover, which requires:

- Aligning work processes and software tools to produce the required information

- Educating staff

- Executing the information handover

- Checking for compliance against the strategy and plan

- Continuous improvement

Information technology developments for the ways in which facility information can be specified and 
managed mean that the handover of information can be greatly improved, particularly in relation to its reusability and its quality assurance. This guide (Part 1) covers methodology, technologies and standards which can greatly enable this process.

Additional facility type-specific guidance is planned for a series of Parts 2 of the CFIHG. These will describe case studies, specific standards and data forms applicable to different capital facility types, e.g., general building, process plant and transportation infrastructure. 


\section{Introduction}

\subsection{Background}

Developed nations invest a substantial portion of their gross domestic product in capital facilities their planning, design, construction, operation, maintenance, renovation and decommissioning. According to the U.S. Census Bureau, over $\$ 370$ billion was invested in new facilities, facility renovations and additions in the United States in 2004. This figure excludes residential facilities, transportation infrastructure such as bridges and roads, and facility operation and maintenance costs.

The global capital facilities industry could perform more efficiently and is under increasing pressure to do so. A number of studies have addressed this issue and provided analyses and recommendations:

- American Institute of Architects (AIA) Interim Report. A Response to "Collaboration, Integrated Information and the Project Lifecycle Cycle in Building Design, Construction and Operation" (WP-1202): a Report of the Construction Users Roundtable (CURT). 2004.

- Construction Cost Effectiveness Task Force, The Business Roundtable. The Business Stake in Effective Project Systems. 1997.

- Construction Users Roundtable Architectural/ Engineering Productivity Committee. Collaboration, Integrated Information and the Project Life Cycle in Building Design, Construction and Operation (WP-1202). 2004.

- The Dutch Process and Power Industry Association (Uitgebreid Samenwerkingsverband Proces Industrie-Nederland - USPI-NL). Reaching the Process Industry Vision: Roadmap to Competitive Advantage via Sharing and Storing Plant Life Cycle Data. 2002.

- FIATECH. Element 9 Tactical Plan, Life Cycle Data Management and Information Integration. In Capital Projects Technology Roadmap. 2004.

- Gallaher, Michael P., Alan C. O’Connor, John L. Dettbarn Jr. and Linda T. Gilday. National Institute of Standards and Technology (NIST). Cost Analysis of Inadequate Interoperability in the U.S. Capital Facilities Industry (NIST GCR 04-867). 2004.

- Rethinking Construction: report of the Construction Task Force to the Deputy Prime Minister, John Prescott, on the scope for improving the quality and efficiency of UK construction. 1998.

Based on the experience of other industries, particularly manufacturing, there is increasing conviction, evidenced by the reports cited above, that the capital facilities industry could improve performance by leveraging information technology to reduce costs and speed execution of business processes that span multiple organizations along the entire supply chain. This has been called "X-engineering" defined as, "the art and science of using technology-enabled processes to connect businesses and companies with their customers to achieve dramatic improvements in efficiency and create value for everyone involved" (Champy 2002, page 3). In this approach, "A certain level of standardization is required to achieve the level of connection necessary for smooth, full flow of information, product, and money" (Champy 2002, page 76).

NIST GCR 04-867 is of particular interest because it identifies and quantifies the efficiency losses in the U.S. capital facilities industry attributable to inadequate interoperability, defined as "the ability to manage and communicate electronic product and project data between collaborating firms and within individual companies' design, construction, maintenance, and business process systems" (NIST GCR 04-867, p. ES-1). The researchers very conservatively estimated those losses to be $\$ 15.8$ billion in 2002 in the United States, excluding the losses for residential facilities and transportation infrastructure.

The reports cited above identify the major obstacles to improving interoperability within the capital facilities industry:

1. There is a lack of understanding on the part of industry participants of how to achieve integrated information and workflows through the application of information technology.

2. There are gaps in the availability of information technology tools and data standards to support 
integrated information and workflows throughout the facility life cycle.

3. Current industry structure and business practices, including procurement practices and regulatory, insurance and contractual requirements, present obstacles to integrated work and information flows.

\subsection{Business Case for Change}

In NIST GCR 04-867, RTI International and the Logistics Management Institute calculated the costs of inadequate software interoperability by constructing a "hypothetical counterfactual scenario.” In this scenario, data exchange and access for all work processes related to design, construction and facility management were unencumbered by data exchange issues. The cost difference between the hypothetical scenario and the real world scenario yielded the $\$ 15.8$ billion economic loss estimate. The full report can be accessed at: http://www.bfrl.nist.gov/oae/publications/gcrs/04867.pdf.

Clearly quantifiable costs were categorized as:

- Avoidance - costs incurred to prevent or minimize the impact of technical interoperability problems

- Mitigation - costs of activities responding to interoperability problems, including scrapped materials costs

- Delay - costs incurred when interoperability problems delay completion of a project or the length of time a facility is not in normal operation

The authors did not include other costs they considered too speculative, such as opportunity costs or costs to tenants. As a result, the $\$ 15.8$ billion estimate is very conservative.

The cost data were gathered from seventy (70) organizations: nineteen (19) architecture/ engineering firms, nine (9) general contractors, five (5) specialty fabricators and suppliers, twenty-eight (28) owners and operators, two (2) software companies and seven (7) research consortia. Data were gathered through focus groups, interviews and surveys. Appendix B contains the survey instruments used.

Costs were reported by stakeholder group, type of cost and facility life cycle phase. The facility life cycle was divided into three major phases:

- Design

- Project initiation

- Planning

- Design programming

- Site selection and acquisition

- Conceptual design

- Engineering analysis

- Contract documents

- Construction

- Operations and maintenance (O \& M)

A fourth phase, Decommissioning, was included in the surveys. However, insufficient data were received upon which to base cost estimates. 


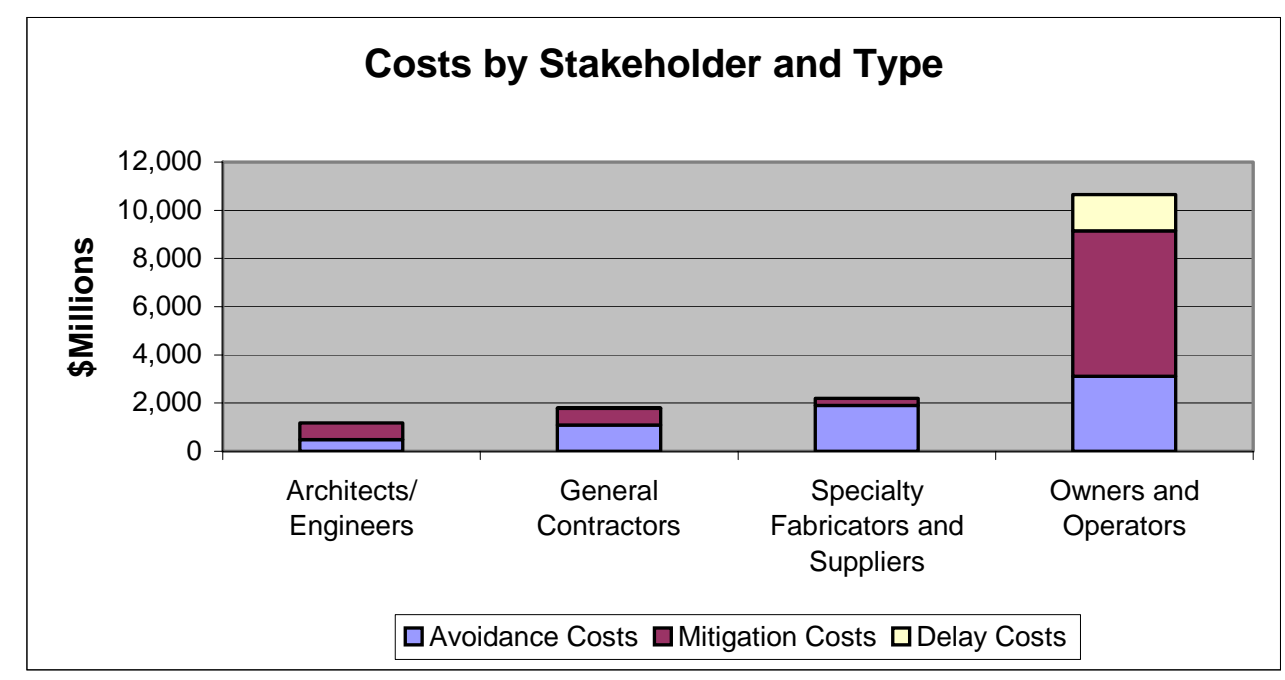

Figure 1: Cost by Stakeholder and Type

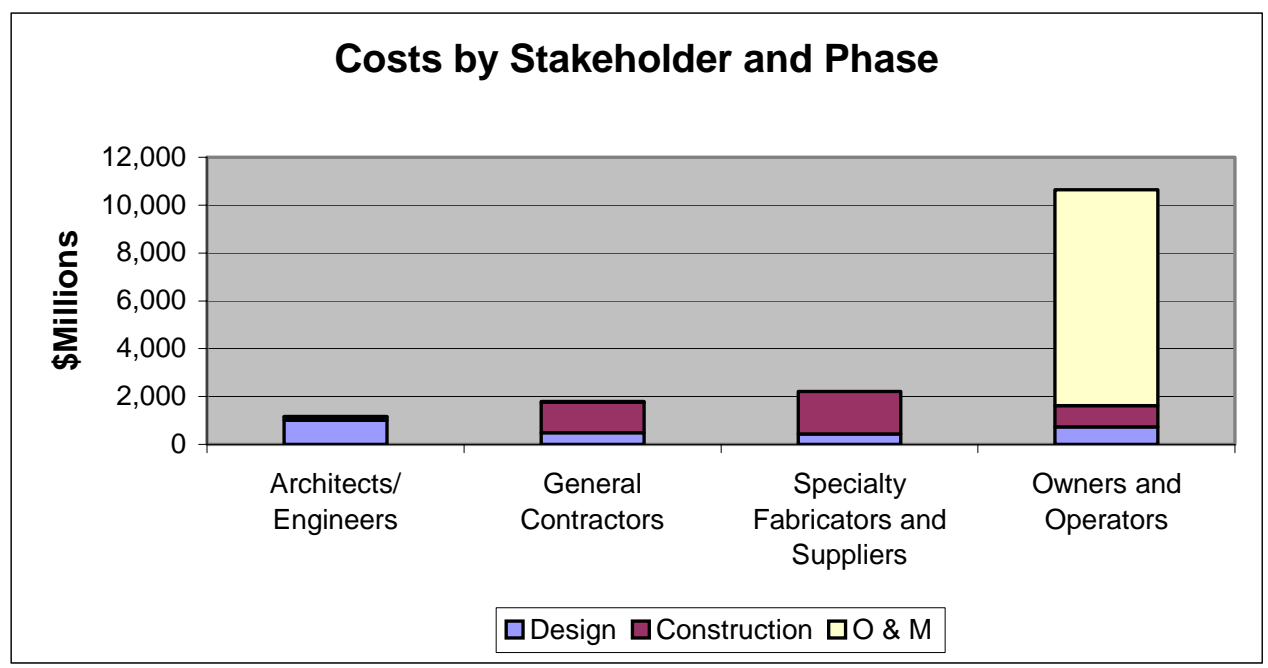

Figure 2: Cost by Stakeholder and Phase

The highest costs were incurred by owners and operators (OOs), and $85 \%$ of those costs were incurred during operations and maintenance. The major cost was time spent finding and verifying facility and project information. Operations and maintenance personnel were estimated to have spent $\$ 4.8$ billion during 2002 verifying that documentation accurately represented existing conditions and another $\$ 613$ million transferring that information into a useful format.

As defined in NIST GCR 04-867, "any corporation or institution that owns, maintains, and/or operates a capital facility is considered an OO” (pages 1-14). This definition includes corporations, real estate management companies, real estate investment trusts (REITs), and government agencies, such the U.S. General Services Administration or Department of Defense. The report suggests that one way to limit interoperability problems is to have the OO stakeholders involved in the early planning for the design and construction phase of the work. "Owners and operators, in particular, were able to illustrate the challenges of information exchange and management due to their involvement in each phase of the facility life cycle. In summary, they view their interoperability costs during the operations and maintenance phase as a failure to manage activities upstream in the design and construction process. Poor communication and maintenance of as-built data, communication failures, inadequate standardization and inadequate oversight during each life-cycle phase culminate in downstream costs. This can be seen in the quantification of substantial costs related to inefficient business process management and losses in productivity for operations and maintenance staff” (NIST GCR 04-867, p.7-1). 
Most stakeholders believed that OOs should take the lead in addressing interoperability issues because they set and drive business and system requirements, in addition to bearing the majority of the costs of lack of interoperability. Top management leadership is required to identify the players and facilitate agreement among them. This was the approach taken by the U.S. semiconductor industry to establish interoperability standards. The report points out, however, that most OOs interviewed did not see the financial incentives for "stepping up to the plate" to improve interoperability.

The report also notes that information about capital facilities is much more comprehensive than the geometric model and surrounding technical specifications and that interfaces are required with human resources, financial, purchasing, project management and accounting and asset management information systems. This insight challenges the traditional approach to interoperability, which focused on the ability to exchange data between like systems, particularly computer-aided design / computer-aided engineering (CAD/CAE) systems.

The seventy businesses participating in the study identified interoperability of procurement, project management, construction and financial systems as a high priority. They wanted to see CAD interoperability extended so that the same data and software could serve both design and construction. They also identified challenges in moving beyond the status quo:

- Delivery models must motivate all participants to optimize value of the end result, realizing that motivation derives from financial gain. There is a need to articulate project goals, define metrics and experiment with contract alternatives that link participants' financial rewards with the project's goals.

- The industry must develop tools and work processes to integrate across multiple disciplines.

- Information must be shared on a real-time basis.

\subsection{Realigning the Delivery Model}

In 2004 the Construction Users Roundtable (CURT) released a white paper (WP-1202), Collaboration, Integrated Information and the Project Lifecycle in Building Design, Construction and Operation. This paper was produced by CURT's Architectural/ Engineering (AE) Productivity Committee, convened to address the perception of inadequate, poorly coordinated AE drawings that result in difficulties in the field, leading to cost and schedule overruns. The committee concluded, "the goal of everyone in the industry should be better, faster, more capable project delivery created by fully integrated, collaborative teams. Owners must be the ones to drive this change, by leading the creation of collaborative, cross-functional teams comprised of design, construction, and facility management personnel” (CURT 2004, page 1).

In November 2004 the American Institute of Architects (AIA) responded to CURT, "From the architect's perspective, CURT has defined a vision for an integrated and accessible decision-making process that is transparent to all contributors to the design, construction and operation of a facility throughout its lifecycle...In order to achieve the vision described in the WP-1202, the performance of the project team cannot be based on traditional contract documents, but on mutually agreed upon goals, shared responsibilities, shared risk and liability, and compensation” (AIA Interim Report 2004). In responding to CURT's request to identify obstacles to moving forward, the AIA mentioned:

- Adversarial relationships between AEs and constructors reinforced by traditional project delivery, compensation and risk allocation arrangements.

- Short-term thinking on the part of owners who frequently seek the lowest first cost for each phase of development. Owners must commit to a project process that optimizes the overall outcome over the long term.

- Standard contracts that reinforce compartmentalization of team members, rather than support integrated and collaborative effort.

- Current risk management strategies, driven by insurers, that run directly counter to open information sharing.

- Technological barriers, including the cost and rapid obsolescence of technology and the lack of interoperability of advanced building modelling software. 
The AIA response concluded that owners must lead the transformation of the capital facilities industry by committing to an integrated project delivery approach, by willingness to use new models for risk management, contractual and legal relationships and compensation and by supporting these new models when confronted with scepticism from lawyers, insurers and financial institutions.

All stakeholders must realize that more effective project delivery, supported by updated contractual, compensation and insurance models, is in the best interest of the entire industry. Individual companies and industry organizations should combine efforts to effect the necessary structural changes as quickly as possible. Although all stakeholders have incentives to improve project process and performance, it is the owners who gain the most and who have the ability to establish the project process parameters and enforce compliance by all participants. Owners must actively support the necessary change initiatives.

\subsection{Accelerating Technical Progress}

To accelerate progress in resolving the challenges to achieving interoperability, each industry sector should:

- Identify work processes that can be streamlined through the use of structured information handover

- Identify the information requirements of the selected processes

- Assess what is available in structured data formats

- Find out who is working on the development of relevant standards and the utility and maturity of these standards initiatives

- Define and execute a plan for an industry-wide standards solution for information delivery and handover

Additionally, industry sectors and professional organizations should investigate organizational structures and business practices, including procurement practices and regulatory, insurance and contractual requirements, which present obstacles to integrated work and information flows. This will provide the basis for defining more effective operations and business practices, e.g., value stream management and work package optimization.

For example, the American Institute of Steel Construction (AISC) followed this approach to streamline the entire steel design-procure-fabricate-erect cycle. The goal was to increase the use of structural steel by reducing schedule time needed to get steel in place. They invested $\$ 1$ million over five years, starting in 1999. AISC built on the work of the European CIMSTEEL initiative (19871998), adopting CIM steel Integration Standard, Release 2 (CIS/ 2).

AISC was effective in promoting CIS/2 as the standard for exchange of structured information for 3D modelling, analysis, interference / clash detection, fabrication drawings, erection drawings, procurement, construction planning and scheduling. By 2004, fourteen (14) software applications used by the various players in the steel industry supported CIS/2. It is important to understand that AISC achieved this level of success because:

- AISC focused on a well defined cross-organizational business process in the structural steel supply chain.

- The process was supported by a limited set of software tools used to generate paper documents to exchange with other participants in the supply chain.

- Each stakeholder group across the supply chain had economic drivers and benefit opportunities motivating their participation.

- There was a robust and mature standard (CIS/2) supported by sufficient implementation guidance.

AISC achieved the goal of reducing schedule time needed to get steel in place through the use of structured information exchange using an international standard format. They were able to document two projects where the construction schedule was shortened by four months. AISC documents case 
studies and has established a communications plan to present a unified message to the steel industry.

\subsection{Capital Facilities Industry Roadmap}

At the moment, the industry work processes are still entrenched in silos of document production. Many of the structured information standards are still in development and have not been incorporated into general use by the industry. Many software applications do not yet support the standards. In addition, the majority of the players in the market - the owners, operators, tenants, consultants, contractors, regulatory agencies and product manufacturers - are not themselves prepared to operate in a highly integrated and automated environment. The standards will be improved through use and resulting feedback. As project teams demonstrate superior performance utilizing integrated work processes and structured information handover, more companies will begin to test the approach. As more companies use structured data in information handovers, demand will be created for software tools that produce and use such data. How does the ball start rolling? It is the goal of this CFIHG to assist the industry players in making the transition.

In 2002, Uitgebreid Samenwerkingsverband Procesindustrie, Nederland (USPI-NL) ${ }^{1}$ laid out a Roadmap for reaching the goal of a fully integrated facility life cycle data repository, based on structured information standards. The Roadmap (Figure 3) distinguishes between internal and external "data readiness." The two are interdependent. A company cannot exchange structured facility life cycle information if it is not internally ready. Both internal and external data readiness are reached through restructuring work processes and introducing new tools.

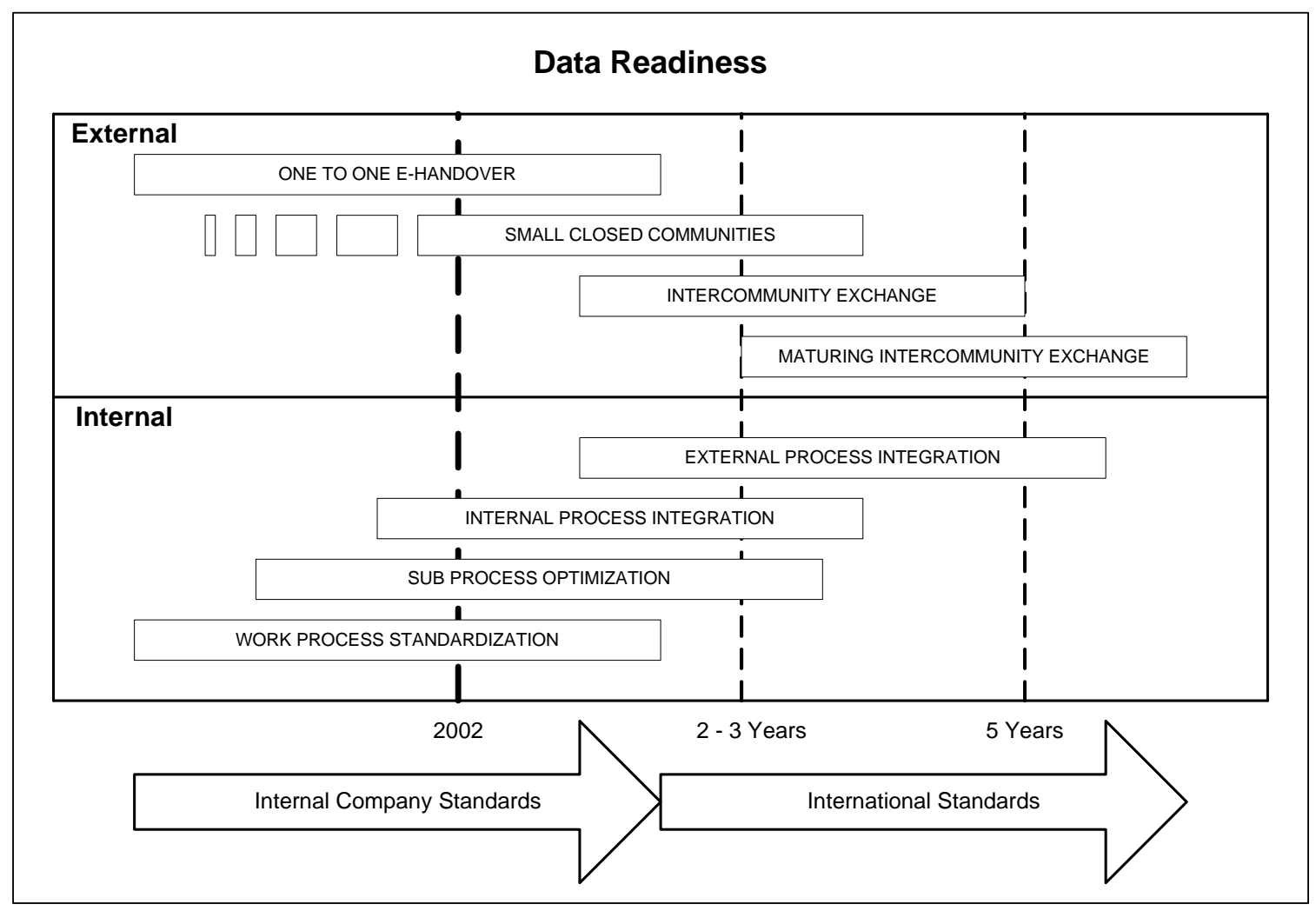

Figure 3: USPI-NL Roadmap

USPI-NL defined four steps each for achieving internal and external data readiness.

\footnotetext{
${ }^{1}$ See www.uspi.nl: Dutch Process and Power industry association that promotes and supports the development and implementation of international for exchange, sharing and management of life cycle plant data and related documents
} 


\subsubsection{Internal Data Readiness}

1. Work Process Standardization: This phase focuses on repetitive work processes within a group or discipline. Every organization continuously attempts to improve work processes by attempting to identify and adopt best practices. This effort is typically bottom-up and pragmatic. It is not concerned with international standards for structured information.

2. Sub-Process Optimization: This phase is still focused on isolated work processes but seeks efficiency by streamlining - removing unnecessary work process steps and automating others. The result is typically internal standardization on software packages and other IT tools.

3. Internal Process Integration: In this phase, the business starts to integrate isolated work processes, reducing data redundancy and achieving the next level of efficiency. Data interdependencies become clear, but the lack of data definitions often makes integration difficult. Businesses realize that exchanging data with external partners will be difficult if data definitions are not clear and unambiguous. They realize the need for international data standards.

4. External Process Integration: In this phase the focus is on exchanging facility life cycle data and integrating external partners into internal work processes. Since the business has already integrated internal processes, it can only achieve greater efficiency by addressing the "missing links" - their external partners. This step is the "X-engineering” discussed above.

\subsubsection{External Data Readiness}

1. One-to-One e-Handover: In this phase, data handover procedures are defined on a project-byproject basis. The owner organization typically defines the content and format of deliverables, based on its internal standards. The internal data readiness of the owner organization dictates the standards used.

2. Small, Closed Communities: Small groups of companies, acting as a community, agree on a common but limited set of generic definitions, and exchange data according to these rules. Often the goal is to improve the procurement process. The Internet has accelerated the move to this phase. There are a number of significant examples that external data readiness has reached this phase.

3. Intercommunity Exchange: This phase is characterized by a higher level of integration. More parties are involved, and not all parties are identified in advance. Parties may have different views of the data. Data definitions are more complex and international standards become important.

4. Mature Intercommunity Exchange: This phase is characterized by many-to-many integration and a high degree of collaboration. Structured information exchange is possible throughout the facility life cycle, from inception through design, procurement, construction, commissioning, operations and maintenance. All parties can exchange life cycle information, international standards have matured and software applications support this approach.

The USPI-NL report projected that the process industry, probably the most advanced construction sector, would achieve a high level of integration and automation in approximately 5 years (2007). Organizations throughout the capital facilities industry are making progress along the roadmap.

\subsection{Purpose of the Information Handover Guide}

The purpose of this Capital Facilities Information Handover Guide (CFIHG) is to assist in accelerating the capital facilities industry's progress by providing guidance on methodology, technologies and standards to improve the efficiency and quality of information handovers throughout the capital facility life cycle. CFIHG provides a framework for the definition and delivery of information packages to be transferred among participants in capital facilities projects, including industrial facilities, commercial and institutional facilities, infrastructure facilities and residential facilities. Information handover strategies must be based on identifying the information created in each phase that will be needed downstream and how it will need to be used. 
An important concept presented here is that of "structured information form." Data in a structured form are machine-interpretable without human intervention. This permits a high degree of system integration and process automation. Comprehensive use of structured data forms in the capital facilities industry is the long-term goal. This guide suggests approaches for moving toward that goal while making incremental improvements in the efficiency and quality of information handovers.

Use of this guide will assist the definition, capture and delivery of information in consistent formats, enabling data exchange among parties and interoperability of systems across organizations in costeffective, quality-assured mechanisms. The ultimate goal is improved delivery and use of capital facilities: lower cost, faster delivery, higher quality.

\subsection{Target Audiences}

This guide is directed to the owners of facilities and the consultants, contractors and suppliers who are involved in planning, designing, building, modifying, operating or maintaining the facility. This audience includes business managers, engineering managers, project managers, information managers and information technology managers involved in one or more life cycle stages of facilities and the organizations responsible for producing, delivering and using the information packages for the design, construction and operation of capital facilities. Among these are organizations that design, engineer, procure, supply, fabricate, install, commission, operate and maintain components of capital facilities; organizations that approve these facilities; and those that provide information systems and services to support these work processes.

\subsection{Organization and Scope of the Information Handover Guide}

The options available to a capital facility project and its participants in handing information over to organizations responsible for subsequent life cycle stages of the facility are so great that a single document such as this cannot provide universal guidance. Part 1 of the CFIHG is applicable to multiple industries and facility types and is intended to highlight the main issues in determining an approach to the handover of information. Part 2 of the CFIHG will contain industry-specific chapters that provide more detailed guidance on the information standards and tools available in each industry. Industry sectors are encouraged to contribute to the further development of Part 2 of this guide.

The scope of the CFIHG is:

- Business process - handover of capital facility information from project inception through facility operations, maintenance and decommissioning

- Industry sectors - building on the principles developed in the EPISTLE Data Handover Guide for the process industries, this guide extends that work to include the requirements and work processes of the other sectors of the capital facilities industries, including commercial, institutional, industrial and transportation facilities

- Information - business and technical information in any form relating to the physical asset

- Information management - preparation, handover, acceptance, storage, access and usage of information.

The following are outside the scope of this guide:

- Information management during the project and post-project

- Security - reference ISO17799, a detailed security standard organized into ten major sections:

1. Business Continuity Planning

2. System Access Control

3. System Development and Maintenance

4. Physical and Environmental Security

5. Compliance

6. Personnel Security

7. Security Organization

8. Computer and Network Management 
9. Asset Classification and Control

10. Security Policy

- Legal admissibility of information stored in various formats.

\subsection{Organization of Part 1}

Part 1 contains general guidance on the handover of information:

- Section 2 describes the overall handover process

- Section 3 addresses the facility life cycle information strategy

- Section 4 deals with developing the business requirements and identifying the appropriate forms of information and metadata to meet these requirements

- Section 5 describes the contents of a project information handover plan

- Section 6 covers the implementation of the project information handover plan

- Section 7 highlights the key points of all sections

- Appendix A is a glossary of terms and acronyms

- Appendix B contains the survey forms used to assess costs of inadequate interoperability for the NIST study described in this section

- Appendix C is a bibliography

- Appendix D lists and provides links to information delivery specifications and standards. 


\section{The Handover Process}

\subsection{Capital Facility Life Cycle}

There are six major phases in the capital facilities life cycle:

1. Planning and Programming

2. Design

3. Construction

4. Project Closeout/ Commissioning

5. Operations and Maintenance

6. Disposal

Each is described below with its high-level information requirements.

\subsubsection{Planning and Programming}

The planning and programming phase is initiated by the end user organization, which may or may not ultimately be the owner of the facility. Information requirements in this phase are driven by the need to assess the condition, capacity, efficiency, operating costs and location of existing facilities in light of business requirements to determine whether the organization should acquire a new facility or modify an existing one(s). This analysis is informed by both a financial and a physical view of the organization's real estate portfolio.

If the determination is made to initiate a facility construction or modification project, the next step is to detail the requirements, or "program," for the facility, including site requirements. Often this is the point when the end user organization hires one or more consultants to assist. This step transitions to the design phase, often with the same consultants.

\subsubsection{Design}

Design is the phase in which the program requirements are translated into a comprehensive physical description of the facility. It is a complex and critical phase, and the one in which the decisions made and quality of information generated have the greatest influence on the eventual outcome of the project. This phase, though relatively brief, creates a large amount of the information essential for downstream facility life cycle phases. There are many specialists involved (architects, civil engineers, structural engineers, building and production systems engineers, interior designers, cost estimators, etc.), and these individuals may belong to one or many organizations. Real-time data sharing between these specialists is critical, yet seldom achieved.

Traditionally, it was program, building material, product and regulatory information that informed design. Regulatory requirements include land use, environmental, building code and testing, among others. Fast track approaches to design and construction began to expand upon the design considerations, introducing constructability and construction sequencing issues into design. More recently, the principles of design for manufacturing and assembly have been introduced to the capital facilities industry. Structural design, for example, has begun to consider the issues of fabrication and assembly (see discussion of the AISC's CIS/2 initiative in Section 1). Now “lean construction” techniques have begun to feed back concerns for optimising utilization of on-site construction materials and resources, even suggesting a just-in-time design approach whereby the design responds to actual material and product availability at the start of each construction activity.

The design phase typically concludes with the procurement of construction services. However, in project deliveries approaches such as design/ build, project alliances and engineer/ procure/ construct, the design phase and construction phase are more continuous.

\subsubsection{Construction}

Construction is the phase during which the facility's physical description becomes a reality. This is the 
phase most analogous to manufacturing because it involves the coordination of material and product deliveries, subassembly activity by subcontractors and sequencing and execution of on-site activities. Additional activities include management of environmental and safety programs and meeting various inspection and testing standards.

Organizational relationships during the construction phase vary considerably with delivery method (design/ bid/ build, design/ build, engineer/ procure/ construct, construction manager at risk) and with project type (infrastructure, commercial building, process plant).

The primary information source for the construction phase is the information describing the facility created in the design phase. This has traditionally been transmitted via construction drawings and specifications. The construction contractor adds information about product sourcing, detailing, fabrication and assembly processes and construction sequencing and schedule.

The completeness and accuracy of the design drawings and specifications have been the major factors in the ability to execute the construction phase on time and on budget. This is an area that has been identified as needing improvement. In 2004 the Construction Users Roundtable (CURT) convened an Architecture/ Engineering (A/E) Productivity Committee to address the issue of errors, omissions, poor coordination and other quality problems in $\mathrm{A} / \mathrm{E}$ documents leading to construction phase schedule and cost overruns (Collaboration, Integrated Information and the Project Life cycle in Building Design, Construction and Operation). There is a hope, expressed by CURT's A/E Productivity Committee among others, that the use of software tools for developing three-dimensional information-rich computer models during the design phase can improve the quality, completeness and coordination of the facility description handed over from design to construction. The use of structured information forms and standard formats for this model data would then permit construction-phase applications, such as CNC (computerized numerical control) fabrication and schedule-linked construction sequencing software, to utilize the design models directly.

\subsubsection{Project Closeout / Commissioning}

When a capital project is deemed substantially complete and the end user can begin occupying and/ or using the facility, closeout begins. This is a very brief phase that marks the transition from construction to operations. It is often the last opportunity to gather facility information from the design and construction teams. For this reason, the handover point from Construction to Closeout/ Commissioning is considered the most critical in the facility life cycle.

\subsubsection{Closeout}

In the Closeout/ Commissioning phase, the construction work is accepted by the owner, necessary documentation is turned over, training is conducted, retained monies are released and a final project accounting is made. Listed below are typical closeout activities:

- Building/ production systems are started up.

- Occupancy certificate is issued, marking substantial completion.

- Facility use begins.

- Owner prepares punch list for contractor.

- Operations and maintenance training is conducted.

- Record plans (as-builts) are submitted.

- Operations and maintenance manuals are submitted.

- Guaranty and warranty provisions are initiated.

- Final inspection is performed.

- Final payment is made.

- Final cost report and as-built schedule are generated.

Although every construction project is closed out, not all are commissioned.

\subsubsection{Commissioning}

Commissioning is the systematic process of ensuring and documenting that all systems and assemblies 
perform according to specification and end user requirements, as well as the owner's operational needs. As facility systems have become more complex and contractors more specialized, traditional methods for start-up and final acceptance have proven inadequate. According to the Total Building Commissioning Project, conducted under the auspices of the U.S. National Institute of Building Sciences, studies indicate that, on average, the operating costs of a commissioned building range from $8 \%$ to $20 \%$ below that of a non-commissioned building. This compares to the one-time investment in commissioning for a building, which ranges from $0.5 \%$ to $-1.5 \%$ of construction.

In a traditional project closeout, information requirements focus on documentation (primarily drawings) of the facility as built, actual project costs and schedule compared to plan, spare parts lists, maintenance products and requirements and equipment and systems training and operations manuals. This information is handed over, frequently as paper documents, by the construction team.

With facility commissioning, the information requirements derive, in addition, from earlier facility life cycle phases. The original facility program defines requirements in terms of the functional, environmental and economic needs of the owner and of the persons using the facility. During the design phase, those needs are translated into physical reality through product searches and selection, calculations and analyses, sketches and drawings, specifications and other descriptive forms. A wealth of information is produced in this phase beyond what is handed off to construction. The concept of continuous commissioning suggests that the information requirements of the commissioning phase be considered from the moment of project conception and that those requirements be captured and documented every step along the way.

\subsubsection{Operations and Maintenance}

Although design, construction and commissioning activities are completed within a few years, the facility life cycle may extend over decades or even centuries. Thus, the operations and maintenance phase is the longest and the most costly. Therefore, it is the life cycle phase that would benefit most from information handovers in structured form. Computerized Maintenance Management Systems (CMMS) and Enterprise Asset Management Systems (EAMS) are two types of software products that facilitate the management of operations and maintenance information, from the physical and financial views respectively. Currently, there is little ability to populate these systems with the information handed over from closeout/ commissioning without extensive, costly and error-prone human intervention. NIST GCR 04-867 documented a cost of over \$ 9 billion due to lack of interoperability during the operations and maintenance phase in a single year (2002). That conservative estimate was for the United States only and did not include residential facilities or transportation infrastructure (NIST GCR 04-867, p.6-2).

Information requirements for the operations and maintenance phase include legal, financial and physical aspects of the facility. Users of this information include owners, operators (including facility managers and property managers), tenants, vendors and service providers.

- Physical information derives almost entirely from the closeout/ commissioning phase: equipment and system operating parameters, warranties, inspection and maintenance schedules, maintenance and cleaning products and tools and spare parts.

- Legal information includes leases, zoning and building codes and safety and environmental regulations.

- Financial information includes lease or operating revenue, depreciation schedules and operations and maintenance costs.

In addition, the operations and maintenance phase generates its own information base, which can be used to improve facility performance and which informs decisions about expanding or disposing of the facility. This information includes production or occupancy levels, service requests, maintenance schedules, inspection reports, work orders, equipment downtime, operating costs and maintenance costs.

Finally, there are projects that impact the facility during the operations and maintenance phase. 
Examples include tenant buildouts, additions and renovations and major systems or equipment upgrades. Each of these projects has its own life cycle and information requirements and sources. A major challenge with these projects is accurately updating the overall facility information base with the project-specific changes. In highly regulated industries, such as pharmaceuticals, maintaining accurate facility information is a major endeavour.

\subsubsection{Disposal}

Disposal of a facility can be via a transfer of the asset or demolition. If the facility is to be sold, critical information will include both financial and physical performance data: production capacity or percent leased, land value, remaining life of building systems and equipment and environmental remediation requirements.

For demolition, information requirements include, types and quantities of materials to be removed, environmental remediation requirements, salvage value of equipment and materials and force required to collapse the structure. Some of these information requirements extend back to the design phase calculations and analyses.

\subsubsection{Increasing Information Interdependence}

Figure 4 shows the major facility life cycle phases, with the large arrows indicating traditional assumptions about information flow. The smaller arrows indicate the emerging picture of a more complex and interdependent facility life cycle information flow. This indicates the need to extend thinking about information handovers to non-contiguous life cycle phases.

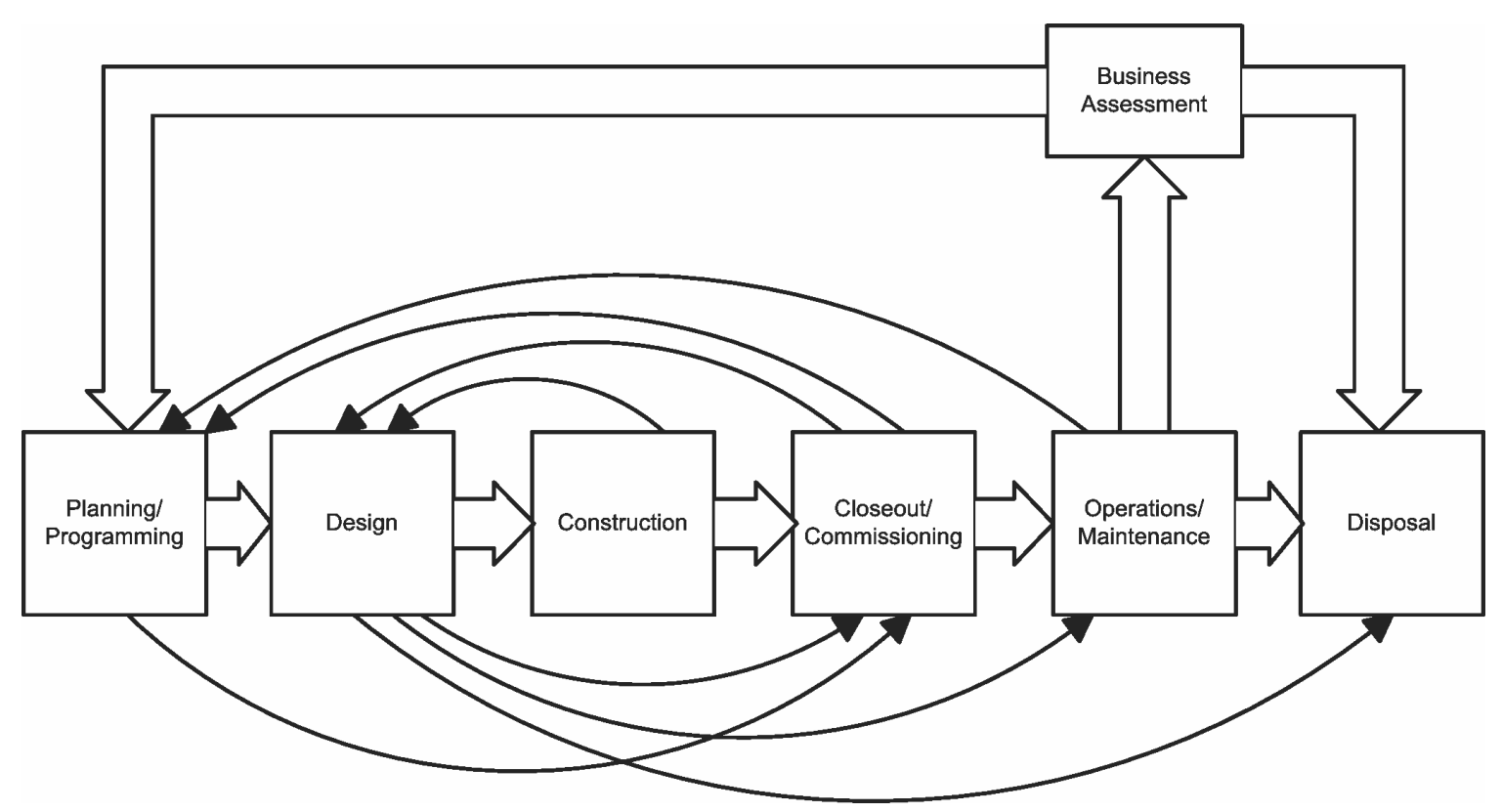

Figure 4: Major Facility Life Cycle Phases

\subsection{Steps in Establishing the Handover Plan}

The overall sequence for the handover of information is shown in Figure 5. 


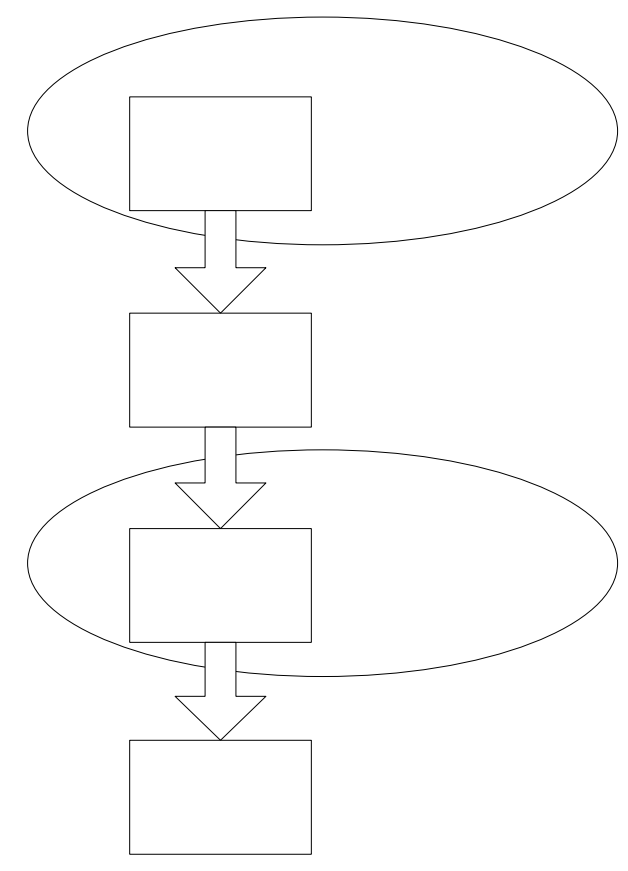

Figure 5: Overall Handover Process

\subsubsection{Facility Life Cycle Information Strategy}

The strategy will be driven by the organization's business purpose and view of its facility portfolio. What does the organization need to know about its facilities to make good facility-related business decisions? Consider the different "views" of the facility: financial, physical, and operational. What are the business processes that need facility information? What specific information is critical to these processes? Who are the participants in these business processes? What software tools are used in these business processes?

The facility life cycle information strategy should clearly prioritize information and assign a business value to various information packages. The strategy should also be consistent with the organization's security policies. Section 3 provides more detail on developing a facility life cycle information strategy.

\subsubsection{Handover Requirements}

In this step you will define the appropriate information form and format for each information package to be handed over and also consider the metadata to be associated with each information package. This step will inform the Project Information Handover Plan. Section 4 provides more detail on determining handover requirements.

\subsubsection{Project Information Handover Plan}

This plan not only covers the information handover requirements, but also covers responsibilities and implementation methods. This is described in Section 5. Industry-specific guidance in this regard will be provided in Part 2 of the CFIHG.

\subsubsection{Implementation}

This step includes technical implementation as well as establishment of project procedures, contractual responsibilities and training programs. Section 6 discusses implementation of the project information handover plan. 


\section{Facility Life Cycle Information Strategy}

Some of the information created in a design or retrofit project informs facility operations for decades. Other information is useful only for the execution of the construction work. Still, other information is required for regulatory compliance regardless of functional value. In establishing a facility life cycle information strategy, the organization examines the business regulations, decisions and processes that require facility information and defines the precise information required by each (known as an "information package"). It prioritizes information packages based on business value. For example, a comprehensive inventory of light fixtures might be helpful, but that information may have lower business value than information required by U.S. Food and Drug Administration regulations or to operate production equipment safely. If a certain information package is used in many business processes, its value increases. Another way to identify high-priority information packages is by looking at businesses processes that are inefficient and/ or costly due to lack of information. This is the approach taken in NIST GCR 04-867. Appendix B contains the survey forms used in the NIST study to identify costs due to lack of information in proper formats. These can be used in combination with your organization's labor rates to quantify such costs within your operations.

Once the organization has identified its high-priority information packages, it then determines when in the facility life cycle those information packages are created and by whom. Some information packages may be created across multiple life cycle phases and by several different organizations. This is typically the case with commissioning information.

Information handover should be based on the information packages required throughout the life cycle of the asset. Thus, information requirements at each handover point should be determined based on which information will be needed at any point downstream, and not just by the next-phase participants. For example, although it may not be important for the contractor to know the reserve capacity of a facility's cooling system, that information will be important if the facility is ever expanded or converted to another use. Therefore, that information should be required at the handover point from design to construction. It will be critical to identify the next user of each information package as well as the party responsible for receiving each information package, ensuring its completeness and maintaining its integrity until its next use.

By defining the precise contents of high-value information packages-when, how and by whom those packages are utilized and when and by whom the information is created-the strategy provides guidance to all participants in capital facility projects on appropriate information handover requirements and also informs the issue of appropriate data formats (discussed in greater depth in Section 4).

\subsection{Contents of the Facility Life Cycle Information Strategy}

It is critical that those making day-to-day decisions on capital projects understand the high-level purpose of information handover. By communicating the ultimate use and relative importance of various information types, the facility life cycle information strategy permits project managers and contractors to make appropriate decisions about handovers on their projects. In addition, the facility life cycle information strategy serves as the source document for detailed handover requirements and project-specific handover plans and for integration with enterprise applications.

The major sections of the facility life cycle information strategy should include, at a minimum:

- Management policy statement, stressing the business importance of successful information handover

- Conformance of information handovers with company policies regarding:

- Contracts and procurement policies

- Legal and regulatory compliance 
- Security

- Allocation and management of information technology resources

- Identification of major information packages, the life cycle phases in which they are created and the business processes in which they are used

- Assigning responsibilities for:

- Establishing appropriate contractual and procurement terms to ensure that required information packages are handed over

- Ensuring that security policies are enforced during information handovers

- Seeing that information handovers occur on a specific project

- Establishing the system infrastructure for receiving information handovers

- Assuring the quality of information handed over

- Maintaining and managing handover information over time

\subsection{Where to Begin}

Owner/ operator organizations already define information handover requirements at key project milestones, typically via contractual provisions. For example, the specifications require the contractor to hand over equipment manuals and spare parts lists. Although the approach recommended here concerns electronic handovers and a more complete definition of the contents of the information package, it can build on existing handover requirements. Organizations can also look at the information required for their computerized maintenance management systems (CMMS) and enterprise asset management systems (EAMS) as a starting point.

The handover to Closeout/ Commissioning is one of the most critical. There are many resources on the information requirements of commissioning. These include, among others:

- U.S. National Institute of Building Sciences (NIBS). Total Building Commissioning Project. http://sustainable.state.fl.us/fdi/edesign/resource/totalbcx/guidemod/docs/01nov98.html.

- U.S. General Services Administration (GSA). Whole Building Design Guide http://www.wbdg.org/project/buildingcomm.php.

- U.S. Department of Energy (DOE), Federal Energy Management Program (FEMP). Model Commissioning Plan and Guide Specifications, Version 2.05. 1998.

In addition, the Operations and Maintenance Support Information (OMSI) for Facilities Project Program, also referred to as "Technical Operating Manuals," provides a process and a product that captures and organizes key information produced during the design, construction and final acceptance of a new facility acquisition or major rehabilitation. The OMSI scope of work helps ensure that virtually all as-built architectural and technical product and system information will be available in a standardized, user-friendly format for use over the life cycle of the facility.

- Naval Facilities Engineering Command (NAVFAC). Operations and Maintenance Support Information (OMSI) for Facility Projects. http://www.navfac.navy.mil/doclib/files/11013_39.pdf.

See: http://www.nibs.org/FMOC/SGML-DTD.pdf.

In the course of developing data exchange standards, standards bodies and industry consortia have defined a number of useful information packages, which include:

- IGES (Initial Graphics Exchange Specification): exchange of drawings and 2D/3D geometry.

- ISO (International Organization for Standardization) 10303 Standard for the Exchange of Product Model Data (STEP): a comprehensive description of the digital design data needed to span the entire life cycle includes subsets, known as application protocols (APs), for specific purposes or activities. Among these are:

- AP 203 - Configuration-Controlled 3D Design of Mechanical Parts and Assemblies

- AP 221 - Functional Data and their Schematic Representations for Process Plants

- AP 227 - Plant Spatial Configuration

- ISO 15926: Integration of Life-Cycle Data for Process Plants Including Oil and Gas Production Facilities that are designed to provide a comprehensive standard for the description of process 
plant facilities.

- CIM Steel Integration Standards/Release 2 (CIS/2): electronic data interchange among applications for steel design, analysis and manufacturing. The American Institute of Steel Construction (AISC) offers explicit guidance, in their 2005 Code of Standard Practice for Steel Buildings and Bridges, for the use of this standard when a digital building model replaces contract documents and is to be used as a means of designing, representing and exchanging structural steel data for a project.

- The International Alliance for Interoperability (IAI) Industry Foundation Classes (IFCs): standard for information sharing and interoperability of intelligent digital building models developed in object-based systems.

- Building Life Cycle Interoperable Software (BLIS): project to implement the IFCs through a set of use cases that define the work process that creates an information package, the work process that uses the information and the information package contents. Use cases have been defined for:

- Design to design (geometry view)

- Client briefing/ space planning to architectural design

- Architectural design to heating, ventilating and air-conditioning (HVAC) design

- Arch/ HVAC design to quantities take off/ cost estimating

- Arch/ HVAC design to thermal load calculations/ HVAC system design

- Arch/ HVAC design to construction management/ scheduling

- FIATECH's Automating Equipment Information Exchange (AEX): XML schemas for the exchange of equipment information.

- Open Standards Consortium for Real Estate (OSCRE) Capital Project Handoff Working Group: electronic data collection templates to collect, the capital facility information on building components and systems needed to populate computerized maintenance management systems (CMMS), enterprise asset management (EAM) and financial systems.

There are many organizations working on the development of data exchange standards for the capital facility industry. The American Institute of Architects Technology in Architectural Practice Knowledge Community maintains a web site that lists many of these organizations and the areas in which they are working: http://www.building-connections.info. It also provides links and contact information for these groups. FIATECH also provides a Data Standards Clearinghouse as part of its Web site: http://www.fiatech.org/projects/idim/dscdata.htm. This Data Standards Clearinghouse provides summary information about the listed standards as well as links to the underlying sponsor organizations and standards efforts. 


\section{Determine Detailed Handover Requirements}

The facility life cycle information strategy:

- Specifies information required for decision-making, work processes and regulatory compliance information packages

- Prioritizes these information packages

- Identifies by whom and when in the facility life cycle these information packages are created

- Identifies by whom or what process and when in the facility life cycle these information packages are updated or used.

In this step, you will define the characteristics of the prioritized information packages and determine the preferred form and format for each.

\subsection{The Uses of Handover Information}

The way in which information is to be used determines the properties and appropriate form and format of the information. Issues that need to be considered include:

- Which version(s) of the information package is required

- Whether the information will be kept up to date or frozen at the point of handover

- What the legal requirements are for the retention of the information (these vary by jurisdiction and facility types)

- How long the information will be retained

- How frequently the information will be accessed and updated

- Access requirements: who or what system(s) will use the information and where it will need to be accessed (office, field, production floor, etc.), access for view only or for update.

\subsection{Characteristics of Information Packages}

There are three major properties of each information package to be defined:

- Status defines the exact version(s) of the information package required for handover.

- Type defines whether or not the information package should be modified after handover.

- Retention defines how long the information package must be maintained.

Type and retention are the primary determinants of preferred form and format.

\subsubsection{Status}

As information moves through a project, its status is changed, normally under configuration control. For example, a drawing may start as "issued for comment." After review, an authorized person might change it to "issued for construction," and finally at the end of the project it will be updated to "as built.” An initial standardization step is to define the status terms to be used.

For each information package, it will be necessary to identify which status is to be handed over. Much important information will be required in "as built" status. It should also be determined whether the information is needed in more than one status, such as "issued for construction" and "as built."

\subsubsection{Type}

Information is either static or dynamic. Static information represents a certain moment in time. Dynamic information should be updated to reflect any changes in the facility.

When the creation of static information has been completed, it is never updated. Examples include certificates, standard drawings, technical specifications and inspection reports. Although there may be subsequent inspection reports, these are not "revisions" or "versions" of previous ones. 
Dynamic information requires more formal information management than static information and generally has a greater frequency of access. Industry regulations and quality systems require that the latest version of the information be made clear to the end user. It may also be necessary to maintain the revision history of the information. Examples of dynamic information include facility layouts, process flow diagrams, equipment data sheets, loop diagrams and lists of safety-critical equipment. All information that is still part of the design cycle is, by definition, dynamic information.

Determine whether each information package is:

- $\quad$ Static

- $\quad$ Dynamic with past revisions discarded

- $\quad$ Dynamic with revision history maintained

- All versions required

- Specific number of previous versions to be maintained

\subsubsection{Retention}

All information designated for handover should have a purpose. When the information is not available, there are consequences to the business. The severity of the consequences and the rapidity with which they are incurred are good measures of the importance of the information and dictate the appropriate level of effort and expense that should be put forward to ensure its availability. On the other hand, if there are no consequences when the information becomes unavailable, then careful consideration should be given to whether that information should be included in the handover requirements. For example, it is difficult to imagine a reason to handover transportation and packing details for equipment that has arrived safely on site and has been successfully commissioned. Of course, legal retention and regulatory requirements may demand the maintenance of information that has no operational value.

The following retention codes are a minimum set for categorizing information packages:

- $\quad$ Essential: Information required for the operation of the facility. Without this information, an unacceptable risk would be created with regard to reliable operations and safety. This information must be retained for the full life cycle of the facility.

- Legally Mandatory: Data that are not expected to be referenced on a regular basis in the operations phase but for which there is a legal or contractual obligation to archive the information for a specific retention period. The retention period must be explicitly defined.

- $\quad$ Phase Specific: Data developed in one facility life cycle phase that are deemed useful for a subsequent phase but not for long-term operations. The use phase must be specified.

- Transitory: Data that are not required to be referenced in any subsequent life cycle stage. These data need not be included in the information handover plan.

Determine the retention code for each information package. It may be preferable to define degrees of business criticality rather than a single "essential" category.

\subsection{Information Forms and Formats}

\subsubsection{Overview}

Paper has been the traditional medium used for the transfer and storage of capital facility information. However, it has proved particularly unsuitable for the use, management and maintenance of such information. Organizations may continue to require information to be handed over in paper form as records, most often in conjunction with digital surrogates. It should be clearly noted in the handover requirements where this is required.

Increasingly, however, facility information is produced and managed electronically. Examples include correspondence, cost estimates, purchase orders, analyses, drawings and CAD models. However, much electronic information is still held in documents that do not have a formal structure. Most correspondence, including project reports and drawings, fall into this category. For these documents, 
the only way to interpret the contents or to check their quality is for someone to actually read them.

Advanced systems can now provide facility information in a structured form that is immediately machine-interpretable. This development advances productivity and reduces errors. It permits the use of computer tools to assist in managing, using and checking the data. A common example is a database. Even graphics and drawings can now be managed in a structured form.

There are four major categories of information forms and formats. Figure 6 identifies their comparative longevity and reusability. A discussion of the forms and formats follows.

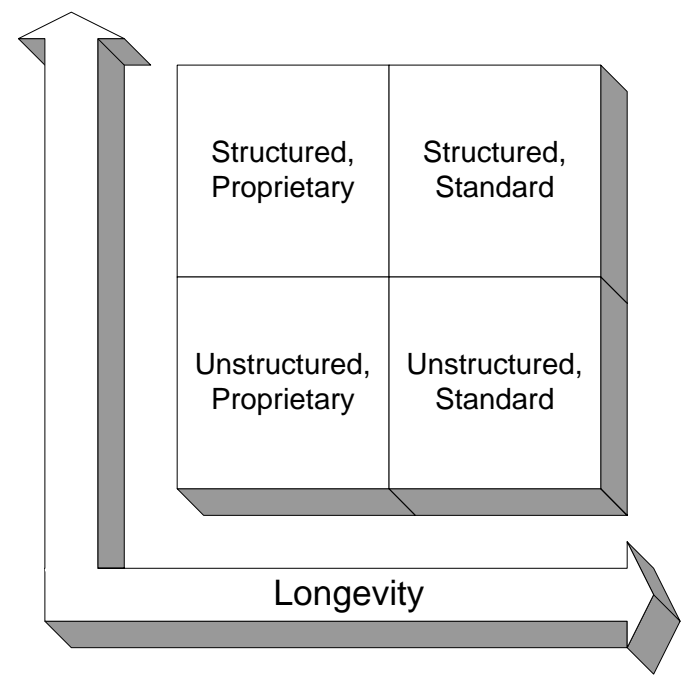

Figure 6: Longevity and Reusability of Information Forms and Formats

\subsubsection{Proprietary Format}

This is the format created by specific software applications such as CAD or word processing programs. It is also sometimes referred to as "native" format. Proprietary is the more significant term, however, because it means that the format is the property of a single software vendor. At any time, the vendor can modify the format. If this happens, archived data maintained in the format may no longer be usable in current versions of the application. Also, a vendor may cease doing business or discontinue the products that output the format. Either of these circumstances threatens to render the proprietary data unusable.

Very often, the owner/ operator uses a particular software application and requests information in that application's proprietary file format. This approach permits reuse in the authoring software but may limit the ability to share the information with other organizations or to use the information when the current generation of software is replaced. As new generations of design software produce increasingly information-rich models, there is the potential for reuse of that information in an increasing number of parallel and downstream processes. Proprietary formats, under these circumstances, become problematic.

\subsubsection{Standard Format}

There are two types of standard formats:

- "Ad hoc standards" refer to formats that may have originated with a single vendor, but have been made publicly available and are supported by multiple vendors and products. Relevant examples of ad hoc standard formats include DXF and PDF. Since the format specification is published, anyone can write an application to access data stored in that format. This assures data longevity.

- Formal standards are those maintained by an official standards development organization, such as 
ISO or ITU. In addition to the advantages of data longevity described above, these standards are typically developed through a consensus process that considers the information requirements of multiple organizations. Thus, formal standard formats may be more flexible and useful.

Standard formats are preferred for any data that will be archived for an extended period.

\subsubsection{Structured Data}

"Structured data" means that the data can be accessed and manipulated directly by computer programs without human intervention. In this form, information adheres to a well-defined model. Structured information may be quantitative (such as structural analysis data), descriptive (such as finishes or coatings) or graphical (such as schematic diagrams, scaled drawings or 3D CAD models). This information form allows for automated - and therefore cost effective-search, retrieval and update, while maintaining the intelligent information content.

There are a number of proprietary structured data models. While useful in achieving the benefits of structured data for a limited number of collaborators during specific life cycle phases, no proprietary models support the full range of facility life cycle activities and their participants. Although proprietary models demonstrate to a limited extent the benefits of a structured approach, common models that adhere to international information standards are preferred. Use of such standards also avoids data being locked into a format controlled by a single vendor.

Examples of structured and standard data formats include ISO 15926 and the International Alliance for Interoperability's (IAI) Industry Foundation Classes (IFCs). Structured standard formats are preferred for information that will be used in downstream automated processes or updated regularly throughout the life cycle of the capital facility.

\subsubsection{Unstructured Data}

Not many computer applications create structured data sufficient for interchange among the other capital facility applications. For example, the common practice of documenting equipment data in a spreadsheet does not allow interpretation by the other applications used in the design, procurement and installation of equipment. Any data that cannot be machine-interpreted are "unstructured."

Electronic images are a type of unstructured data. This format is simply a dot pattern that can be interpreted by a viewer, like a photograph. Often, paper documents are brought into the electronic environment by scanning them into image format. Although these electronic images are suitable for read only access, updating information in this format is difficult. Some applications, such as digital photography, create images as their native format. There are a number of both ad hoc and formal standards for image data: ITU Group 4, TIFF and JPEG are widely used.

The electronic image is the simplest format that allows controlled multiple access of information from one master source. By selecting an electronic image format standard, the cost of information upgrading for future innovations in file formats can be minimized. With information in electronic image format, filing, retrieval, tracking and monitoring can easily be supported with the proper application of metadata, but machine interpretation is difficult or even impossible.

\subsubsection{Hard Copy}

Although organizations continue to require certain documents in hard copy, this is the most difficult information medium to manage and secure. Also, it is the most expensive to access, due to the need for physical handling. Hard copy may be required to maintain originals with signatures, stamps or other approvals for legal purposes, although this practice is declining. To improve access to the content of documents maintained as hard copies, it is recommended that they also be archived as electronic images.

\subsubsection{Considerations in Selecting Preferred Form and Format}

The use of the data through the life cycle of the asset should be the prime consideration in selecting 
the preferred form and format of the information to be handed over. This should be offset against the cost and difficulty of delivering the information in that way. Identify the preferred form and format of the information, taking into account:

- Information priority

- Information type-static or dynamic

- Retention period

- Software application(s) to be used downstream and which formats they support

- Need to share the information with external organizations

- Frequency of update

- Costs and difficulties in getting the information into the preferred form and format

- Capability of the creator of the information to deliver the information in the preferred form and format.

\subsubsection{Costs and Benefits of Information Forms and Formats}

\subsubsection{Structured vs. Unstructured}

The handover of structured information in a standard format requires the greatest investment in information technology development and training. Priority for structured form should be given to information that is frequently updated, particularly if that information is shown in multiple drawings or other documents. If this priority information is provided in structured form, the other documents will be derivative and therefore automatically generated. By identifying these derivatives, the list of documents required for handover can be reduced. This reduces information management costs and downstream efforts of retrieving, updating and coordinating multiple documents, providing substantial business benefits throughout the facility life cycle.

For example, pharmaceutical manufacturers are required to maintain very accurate documentation of their production facilities. In a classic documentation set, every time a process is reconfigured all drawings (process flow diagrams, schematics, process and instrumentation diagrams, layouts, etc.) must be updated and coordinated. As early as the 1980s, some pharmaceutical companies were exploring building structured data models of their facilities, rather than maintaining drawings. A physical change could be made one time in the structured data model and any necessary drawings could be automatically derived.

Although there are benefits to maintaining any information in structured form, there is less value for information that will never be updated. An example would be the installation instructions for a piece of equipment. This type of information can be accepted in an unstructured form.

\subsubsection{Proprietary vs. Standard}

The next question is whether proprietary format files, rather than standard format, are acceptable. The first consideration is whether a standard format exists for the information required and if the standard is implemented in the relevant software applications. In the absence of a standard format, proprietary formats must be used. There are a number of standard formats at various stages of development, validation and commercial deployment in software products. ISO 15926 is designed to provide a comprehensive standard for the description of process plant facilities. The International Alliance for Interoperability's (IAI) Industry Foundation Classes (IFCs) - the IFC2x Platform Specification to be precise- - has achieved international specification status as ISO/PAS (Publicly Available Specification) 16739. This standard covers the general building type. Certain specialized capital facility types, such as transportation infrastructure, may not be adequately covered by either standard however. There are also emerging a number of business use-specific standards, such as AEX (Automating Equipment Information Exchange), an XML schema architecture that addresses the information handovers along the equipment supply chain from preliminary design to mechanical specification, procurement, installation and operation.

A second consideration in deciding between proprietary and standard formats is the intended life or retention of the information. If the life exceeds 5 years to10 years, a proprietary format is risky, due to the rapid pace of technological obsolescence, and a standard format is highly preferable. In the 
absence of a comprehensive standard, a preservation strategy must be articulated for the proprietary format. This would involve ongoing monitoring of the format and updating of the data as new versions were released, as well as translation of the data if the format were threatened with obsolescence. Consideration of these data preservation costs reveals the life cycle cost benefit of standard formats. However, if the information package has a very short life cycle (less than 5 years), a proprietary format may be an acceptable and less costly option. For example, structured information about temporary facilities may be extremely helpful in dismantling them and reusing their components, but need not necessarily conform to a standard model.

In deciding on a standard format one must assess the level of adoption, the availability of reliable implementations and the cost of using the standard. Also, who will be the downstream users of the data? Will these users have access at a reasonable cost to software that supports the standard? It is also critical to consider the level of technological expertise of the potential information providers. Assuming that a comprehensive standard format is available and well supported by commercial application software, are the potential consultants, contractors and suppliers capable of creating a complete and accurate model? If it is unlikely that the level of technological expertise in the marketplace will support the optimal information handover approach, the facility owner must either provide training or modify the information strategy. Careful thought should be given to whether the short-term cost of providing training outweighs the long-term benefits of having the facility information in structured form and standard format. These benefits include:

- Better information

- Faster access

- Improved operations and maintenance productivity

- Improved safety and emergency capabilities

- Ease of compliance with regulatory requirements

- Ease of compliance with documentation requirements for ISO quality registration.

\subsubsection{Format Specification}

Whether handover information is structured, unstructured, standard or proprietary, a precise file format and version should be specified. Even international standards are constantly evolving and this may cause some problems unless the exact release or version can be identified downstream. Although standard formats typically maintain backward compatibility (i.e., an application that can read version 3 of the standard format can also read versions 1 and 2), there are occasional technology disruptions that prevent backward compatibility. Although this is a less frequent occurrence than with proprietary formats, it is nevertheless desirable to be specific about version of the standard is to be used.

\subsection{Metadata}

Information is organized and classified differently in life cycle stages by different participants and in various industry sectors. In order for information handed over to be useful, end users must be able to organize, extract and present it flexibly. A good metadata schema is critical to managing and providing access to the information.

Metadata are defined as data about other data. Metadata are used to organize the information system and to search for particular items. A comprehensive metadata approach is necessary for long-term data access and preservation through the facility life cycle phases. Metadata requirements should be included in the handover requirements.

The source of the metadata can be internal to the information resource-defined automatically at the time the resource was created - or it can be external and added manually. In addition to other benefits, structured data typically creates and manages a good deal of the metadata required.

There are three basic types of metadata:

- Descriptive metadata identify and describe the information with fields such as creator, title, subject matter, responsible organization and so forth. ISO 12006-2 provides a framework for the 
classification of information about construction works.

- Administrative metadata are used to manage the information and include such fields as intellectual property status, file format, file size, creating system, archiving date, archiving expiration date and archiving refresh interval. This type of metadata is critical to implementation of a long-term facility life cycle information strategy. The Open Archival Information System (OAIS) Reference Model, ISO 14721:2003, defines an archival system dedicated to preserving and maintaining access to digital information over a long term. OAIS separates the details of format and preservation metadata from the other administrative metadata and places them in a separate Format Registry, which is designed to aid in data preservation and to monitor formats. The Format Registry identifies all file formats stored in the archive and their properties, and automates the assignation of preservation strategies.

- Structural metadata describe the internal structure of the information and relationships between its components. They can be used to track the relationship between a single drawing and the set to which it belongs, multiple revisions of the same document or the relationships among files in a compound electronic document (e.g., reference files making up a CAD drawing, or a spreadsheet linked to a document). They can also be used to describe the documents that derive from a particular information package in structured form.

For document metadata, there is an ISO draft standard: ISO/DIS 82045.5 Document management Part 5: Application of metadata for the construction and facility management sector (2004-03-11). It specifies elements and methods for sharing and exchanging metadata for documents in the architecture, engineering and construction and facility management domains. It is designed for use with both electronic and paper-based document management systems and includes all three types of metadata described above.

\subsection{When to Begin}

Handover requirements — content, format and metadata — should be defined in the contract between parties. Unless the information is originally created in the desired form, it may be difficult and expensive to convert. Also, a structured form created after the fact fails to provide the same benefits. A study conducted by the Construction Industry Institute (CII) in the United States in the early 1990s (RS106-1: 3D CAD Link) suggested that the effort to convert facility drawings developed manually or in an unstructured CAD format to a structured model was ineffective in controlling construction costs or schedule, while the use of information-rich models during design did yield such benefits.

Therefore, it is essential that the facility life cycle information strategy and the handover requirements be established before project initiation so that contractual requirements for information handover can be defined. 


\section{The Project Information Handover Plan}

\subsection{Overview}

The facility life cycle information strategy (Section 3):

- Specifies information required for decision-making, work processes and regulatory compliance information packages

- Prioritizes these information packages

- Identifies by whom and when in the facility life cycle these information packages are created

- Identifies by whom or what process and when in the facility life cycle these information packages are used.

The handover requirements (Section 4) define, for each information package:

- Status

- Type

- Retention

- Preferred form and format

- Metadata requirements

- Hard copy requirements, if any.

The project information handover plan brings together this information handover content, format and metadata requirements and the implementation issues for a specific project.

\subsection{Developing the Project Information Handover Plan}

The facility life cycle information strategy and the handover requirements are generalized for any number of locations, facility types, project scopes and delivery methods. The challenge of the project information handover plan is to apply these general requirements to the specific project so that highpriority, correct and properly formatted information packages are dependably, timely and cost effectively handed over by the originating members of the project team.

\subsubsection{From General to Specific}

Important considerations in tailoring the general guidance to the specific project include:

- Jurisdiction-specific requirements, including:

- Retention

- Hard copy

- Wet signatures or physical stamps

- Information handover to the jurisdiction

- Each team member's responsibility for work processes that create priority information packages

- Specific software products in use by team members

- Requirements for information sharing among team members within the project, as well as for handoff to downstream processes

- Each organization's experience and capacity to work with data standards and structured data forms

\subsubsection{Information Quality}

Properties of information for which quality requirements should be assessed include:

- Clarity: The availability of a clear and shared definition for the information - do creators and users of information use the same codes and terms with the same meaning?

- Accessibility: Where, how and to whom the information is or is not available - is the information easily accessible? 
- Usability: Can the information be organized and presented differently for different users? For example, a cost estimator or specification writer views facility information much differently than the design engineer who created it.

- Consistency: The consistency of information from different sources - is the information about particular objects consistent in terms of naming, values and relationships?

- Compatibility: The compatibility of the same type of information from different sources - if the same type of information comes from different sources, is it created in the same way? Are there multiple copies or versions of this information and if so, is there a master copy from which the others are derived?

- Completeness: How much of the required information is available — is the full content of each information package supplied?

- Timeliness: The availability of the information at the time required and how up-to-date that information is - is the current version of the information you require available, and is it available when you need it?

- Accuracy: How close to the truth the information is - is the accuracy of the information known and does it meet your requirements?

- Cost: The cost incurred in obtaining the information and making it available for use - is the information supplied in a form and format that means the cost of maintaining it throughout the life of the asset has been minimized?

Processes must be agreed and put in place to ensure the quality of the information to be handed over and should form a part of the project's overall quality plan.

\subsubsection{Logistics}

The project information handover plan should make clear:

- Who will produce each required information package?

- How will they deliver the information package?

- Who will receive the information handover?

- Where will the handover information be stored?

- Who will be responsible for its management and integrity?

\subsection{Relationship to Facility Life Cycle Information Strategy}

The key point that all project participants must understand is that information should be managed for the whole life of the asset and not just for its immediate use. Information created during the design phase of the project (i.e. for specifying and ordering an item of equipment) is also useful during the operational phase of the asset for other purposes. Therefore, the information must be created and managed not only to meet the immediate procurement need, but also for its reuse throughout the lifetime of that item of equipment.

The goal is to ensure that:

- Data required by future information systems will be immediately available and usable

- Project information deliverables will be suitable for the appropriate life cycle phases:

- Planning and Programming

- Design

- Construction

- Project Closeout/ Commissioning

- Operations and Maintenance

- Disposal

To preserve the integrity of the information both over the duration of the project and over the full life cycle of the facility, a long-term view of the classification and structuring of information is required. A strategy for the management of changes in systems and technology is also needed, although these considerations are outside the scope of this document. 
There will be some cost associated with both the project information planning process and the project team members' compliance with the plan. Avoidance of these costs will lead to significantly greater costs in downstream processes, particularly operations and maintenance, as documented in Section 1. There is always the need to control project costs. However, during the development of the facility life cycle information strategy, the first cost versus life cycle cost of capture and management of various information packages should be analyzed. The organization identifies the priority information packages based on their value. The organization must make an ongoing commitment with each project to reap the long-term cost savings identified through developing and adhering to the project information handover plan.

\subsection{Handover Plan Contents}

\subsubsection{Information Packages}

The project information handover plan should define a comprehensive approach to the consistent creation, management, use and exchange of all information related to both the execution of the project and the priority information packages identified in the facility life cycle information strategy. The plan should document:

- Project-specific information package sources and phase when produced

- All uses of priority information packages generated during the project in subsequent life cycle phases (see Section 3)

- Format for each information package (see Section 4)

- Required metadata (see Section 4)

- Clear assignment of responsibility for all information creation and handover activities.

The level of detail should be such that the receiving information management system can be designed and configured to hold all expected data.

\subsubsection{Handover Methods}

The method of handover will depend to a certain extent on the form of the information to be handed over. Organizations may continue to require information to be handed over as paper records, most often in conjunction with digital surrogates. Where this is required, it should be clearly noted in the project information handover plan.

For electronic handover, there are a number of approaches that can be adopted. Efforts should be made to provide the entire project team controlled access to a shared repository of accurate project information and to minimize redundancy and the effort required to conform multiple versions of the same information. There are a number of possible approaches to doing this:

- The owner/ operator implements an information system and provides controlled access to all project participants, internal and external. Based on project role, the various participants upload deliverables to the information system at the required handover points and/ or retrieve the information required for their activities.

- A project management consultant, application service provider, construction manager or contractor implements an agreed information system, which is populated with information throughout the project by all participants. At commissioning, the whole system, complete with its information, is handed over to the owner operator. Alternatively, a parallel system can be populated with only that project information designated for handover.

- A project management consultant, construction manager or contractor uses his own in-house systems to assemble the information, populates a system for the owner/ operator and then hands over the populated system at the end of the project. This approach can be used where the outside organization already has a well-established infrastructure, but the owner/ operator does not.

- Each organization participating in the project uses its own in-house systems to assemble the information and then transfers the information periodically to the owner/ operator to load into existing operational systems. 


\subsubsection{Responsibilities}

Once the required handover information has been specified and documented, the participants in the project need to agree responsibilities for:

- Creation of information

- Security of information

- Quality of information

- Gathering third party information (e.g. equipment vendor documentation)

- Getting information into the right format

- Assigning metadata

- Implementation of the information management systems

- Managing the information through the project

- Assuming responsibility for the information upon project closeout.

\subsubsection{Timing}

The frequency and timing of information handovers must be settled. Issues to be covered include:

- Will it be a "big bang" at the end of each project life cycle phase, or will the information be built up throughout the project?

- Will trial handovers be required? It is advisable to test the handover technique and participants' understanding of the requirements early on to avoid reworking large quantities of data?

- If data conversion is required, how soon after the end of each life cycle stage will the information be required?

\subsubsection{Method of Transferring Data}

In the past, data were usually transferred on magnetic or optical media, such as 3.5-inch floppy disks, magnetic tapes or CD ROMs. Today, such transfers are usually accomplished by electronic transfer across a public or private data network.

The method of data transfer should be agreed by the parties prior to the exchange of any information. Security issues must be addressed. It may be necessary to hand over certain design or contractual information on paper to meet with legal requirements. The requirements for paper documents need to be carefully considered in relation to the ability to create verifiable copies of information from electronic storage and the legal admissibility of such information.

\subsubsection{Information Quality Management}

The project information handover plan should provide an information quality management framework that describes the information handover in terms of scope, contents, constraints, coding, timing and procedures.

The information quality management framework should address:

- What is to be handed over and in what format

- Required metadata

- How the information is to be handed over and receipt acknowledged

- Time period allowed for verification of transfer and checking

- Quality metrics for the information and the process to ensure that the information is of the required quality

- The procedure to be followed if and when incorrect or incomplete data is found.

For structured information, the information quality management framework can be extended to include:

- Inventory of reference data types, ownership and usage

- Reference data distribution processes, possibly supported by tools between the parties

- Process for identifying and resolving inconsistencies

- Reference data coding structures. 
These topics are covered in more depth in Section 6.

\subsection{Storing and Preserving Handover Information}

Data preservation is a highly complex issue. Paper-based preservation focuses on preserving the physical entity. With digital data, preserving the physical media on which the data is stored solves only part of the problem. Digital preservation requires not only refreshing the physical media and ensuring that it can be read, but also ensuring that the digital data is not changed or corrupted and that programmatic access to the data is maintained.

Media refreshing ensures that data will not be lost due to deterioration of the media on which it is stored. An example of this would be copying data archived on one storage media to new storage media on a scheduled basis. Ensuring that the file is not changed or corrupted can be handled by techniques such as checksum or digital signatures. This is called "bit preservation." With the rapid turnover of devices, processes and software, the more difficult issues are the availability of hardware that can read the media and of software that can display the content.

Archiving the data in active, online storage rather than on external media best solves the media problem. Requiring information to be handed over in formats that are defined by formal standards organizations such as ISO is the best protection against format obsolescence. The longevity of information forms and formats is discussed in Section 4. 


\section{Implementing the Handover Process}

In this step you will align work processes and software tools to produce and deliver the required handover information.

Although this document focuses on handovers from one work process to another and on guidance on information management during the creation process outside its scope, the greatest efficiency will be achieved if the handover process is integrated with the creation process. This will provide a streamlined flow of information throughout the capital facility life cycle.

\subsection{Technical Implementation}

The technical implementation must align the hardware, software, data communications and IT operations to ensure timely creation and delivery of quality information in the proper form and format. The technical implementation must explicitly address each information form and format to be handed over:

- Structured data in standard format

- Proprietary formats

- Electronic Image

- Hardcopy (if any)

For all dynamic information — both standard and proprietary formats - configuration management will be very important. The information content of a given model or document will evolve over the course of the project, and many will continue to evolve through operations and management. However, there may be a need to preserve and access "snapshots" at key points along the facility life cycle timeline. For example, it may be very helpful to compare "issued for bid" to "as built" information in order to troubleshoot operational problems or for litigation support. This means it will be necessary to manage versions of data in both standard and proprietary formats. The correct version must be associated with each state of the information and retrievable as such.

\subsubsection{Structured Data in Standard Format}

The same information may be organized and viewed in many ways by different users or at different life cycle stages. Traditionally, this has resulted in multiple engineering documents containing redundant information just represented differently.

This redundancy creates the potential for coordination errors as the project information evolves, and it creates the need for checking procedures. The iterative checking activity consumes schedule time and project budget. Coordination errors not caught during checking may result in construction delays and rework in the field at additional expense. For many years the goal has been to create a single, unified facility information model from which all "views" of the facility are derived. The use of structured information in standard rather than proprietary format permits information from many organizations to be merged into such an integrated model. How then should this integrated model be structured to support the many and varied views required throughout the facility life cycle?

Another problem arising from the many views of the facility model is the use of different terminology. Although a human interpreter understands that a girder and a beam serve the same structural function, software may not. In addition, in a global economy, in which parties from different parts of the world participate on projects, the risk of misunderstandings increases. It is of utmost importance that there is no confusion about the exact meaning of model data. How then is terminology standardized?

\subsubsection{Technical Solutions}

To support the electronic delivery of capital facility information, industry has undertaken various data 
exchange standardization efforts. Early efforts built on the successes of the manufacturing industries (e.g., aerospace and automotive industries). Initial Graphics Exchange Specification (IGES) was an early example for exchanging drawings and geometry. In the 1990s, the goal of the ISO (International Organization for Standardization) 10303 Standard for the Exchange of Product Model Data (STEP) was a comprehensive description of the digital data needed to span the entire product life cycle. This includes geometry, topology, tolerances, relationships, attributes, assemblies and configurations. In the development of the standard, ISO/ STEP uses a technique called application protocols, which creates subsets of the standard for specific purposes or activities. These application protocols provide very precise definitions of specific information packages (e.g., ISO 10303-221: Process Plant Functional Data and Schematic Representation and ISO 10303-227: Plant Spatial Configuration).

A more recent example of an ISO standard for capital facility information is ISO 15926, which is designed to provide a comprehensive standard for the description of process plant facilities throughout their life cycle. ISO 15926 employs a generic data model that is supplemented with templates and a reference data library to support any view of an information package and the complete life cycle of a facility. ISO 15926 supports mechanisms for the definition of custom templates for accessing and presenting model data in any way the end user requires. Templates can be "layered" to create different levels of abstraction. This is referred to as the "onion model." The appropriate number of layers is still under discussion, so this aspect of the approach is not yet standardized. Figure 7 illustrates the concept.

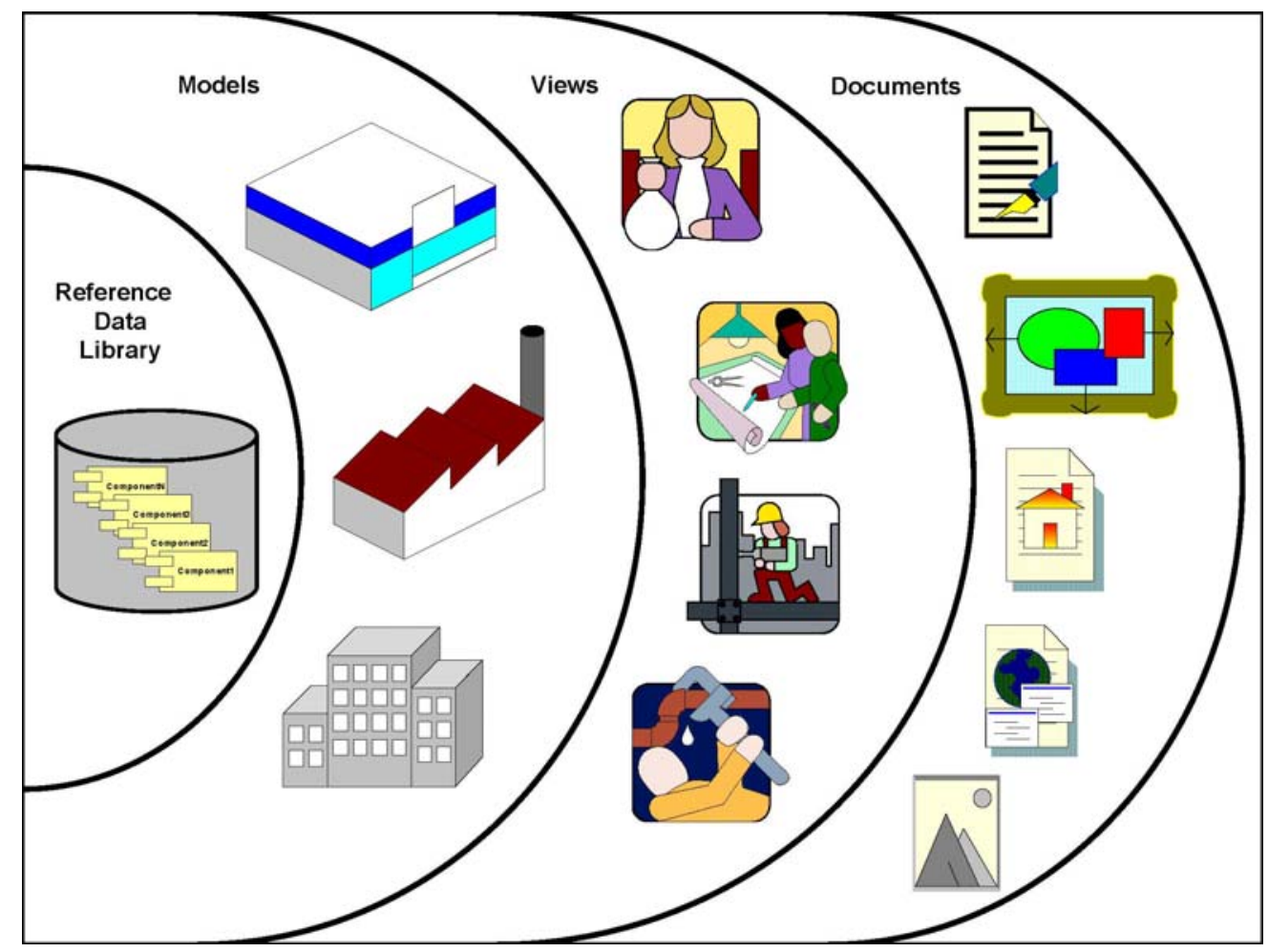

Figure 7: “Onion” Diagram

Other standards development efforts take similar approaches. The CIMSteel Integration Standards/ Release 2 (CIS/ 2) is the product model and electronic data exchange format (file format) for structural steel project information. CIS/ 2 is intended to create a seamless and integrated flow of information among all parties in the steel supply chain involved in the construction of steel framed structures. It has been adopted by the American Institute of Steel Construction as their format for Electronic Data Interchange (EDI). CIMsteel stands for the Computer Integrated Manufacturing of Constructional Steelwork. CIS/2 has been implemented as a file import or export capability by many steel design, analysis, engineering, fabrication and construction software packages (CIS/ 2 Translator Implementations). A CIS/ 2 file exported by an analysis or design program could be imported into a 
detailing program to detail the connections.

The International Alliance for Interoperability is an alliance of organizations in AEC and other industries whose goal is to develop a universal standard for information sharing and interoperability of intelligent digital building models developed in object-based systems throughout all phases of the building Life Cycle. The IAI has published a series of Industry Foundation Classes (IFCs) specifications that define an object-based data model for the AEC industry. Building Life Cycle Interoperable Software (BLIS) is a project to implement IFC standards through a set of use cases, analogous to the application protocols for ISO/STEP. BLIS currently coordinates 60 vendors who seek to support IFC specifications.

FIATECH's vision is enhanced execution of capital facilities projects and operation of capital facilities through "seamless access to all data, information, and knowledge needed to make optimal decisions in every phase and function of the capital project/ facility lifecycle" (Capital Projects Technology Roadmap 2004). In support of this vision, FIATECH has conceived a Technical Framework and has begun development thereof. FIATECH's Automating Equipment Information Exchange (AEX) project is developing XML schemas for the exchange of equipment information throughout the life cycle.

Appendix D provides a listing and links to a number of evolving electronic information delivery specifications and standards. The selection of any of these, as part of an information handover plan, will require due diligence in assessing how well the capital facility information requirements are represented, the availability of commercial implementations, the proven interoperability of the implementations for priority work processes and the level of investment (time and resources) required to apply these to the capital facility projects and partnering work processes. The successful deployment and use of these standards for capital facilities information handovers requires information planning and management across all participants in a capital project, as well as the availability of commercial implementations.

\subsubsection{Proprietary Formats}

Successful handover of dynamic information in proprietary formats requires careful planning and enforcement of standardized working methods. Where this type of information is classified as essential, per Section 4, a preservation strategy must also be in place for the proprietary format. Major issues to be addressed in implementation include:

- Standards for acceptable applications, versions and file formats

- Maintaining file linkages in compound documents, including CAD files with external references and Object Linking and Embedding (OLE) ${ }^{2}$ objects in more general document types

- File naming

- Version control and document statusing

- CAD standards - layering, line weights, etc.

- Particularly with CAD files, the ability to reconstitute a particular "view" of the data-for example, the demolition plan for the second phase

- Metadata to be associated with each file type.

If the information to be handed over is static, an electronic image in a standard format such as PDF is preferred.

\subsubsection{Electronic Images}

Electronic images provide minimal downstream utility but are simple to handover and manage. Metadata are essential to their downstream accessibility. File size and image resolution are also key concerns, and these have a direct impact on the long-term cost of maintaining this information. Implementation issues include specific image format(s) and version(s), resolution of raster images/

\footnotetext{
2 Certain trade names or company products are mentioned in the text to specify adequately procedures and software used. In no case does such identification imply recommendation or endorsement by the National Institute of Standards and Technology, nor does it imply that the procedure or software is the best available for the purpose.
} 
scanning specifications, file naming and metadata.

\subsubsection{Hardcopy}

Implementation of hardcopy handover requires logistical planning. In addition, it is appropriate to maintain an electronic image as a digital surrogate of each hardcopy document to improve accessibility to the content. Even if an electronic image is not delivered, there should be an electronic database that logs the hardcopy documents handed over and their metadata.

\subsection{Project Procedures}

Since the adoption of new tools will undoubtedly change work processes as well as roles and responsibilities, it will be extremely useful to document the project procedures related to information handover, as well as responsibilities. Map the software tools to be used for these procedures.

\subsection{Staff Training}

All persons involved in information generation and handover should understand the following:

- Purpose and use of the information involved

- Life cycle aspect of information (in particular, the need for information to satisfy future life cycle requirements as well as its immediate use)

- Quality assurance issues (how to verify information)

- How to create and use the information

- Security issues such as confidentiality, virus checking and backup

In addition, they will require training on how to use the software to perform the tasks for which they are responsible.

\subsection{Compliance Checks}

The results of implementing the plan should be checked against the published strategy and any discrepancies resolved.

Where the implementation includes multiple companies or organizations, all parties should be included in these checks.

\subsection{Continuous Improvement}

Experience with information handover should feedback to improvements in the process. Lessons learned sessions should be conducted with all participants in information handovers in all facility life cycle stages. 


\section{Conclusions and Recommendations}

The main points to remember in planning and executing information handovers are as follows:

- Failure to establish and enforce standards for information handovers costs the U.S. capital facilities industry at least $\$ 15.8$ billion per year. This cost excludes residential and transportation infrastructure facilities.

- To the extent that a common facility life cycle information strategy can be developed for a large group of capital facility assets, costs will be reduced and benefits amplified.

- Information requirements must be driven by the long-term business needs of the owner/ operator.

- The information forms and formats must be selected in relation to the long-term use of the information. Clear understanding of the information type and retention requirements will greatly assist in selecting appropriate forms and formats.

- All information packages must be structured to support downstream work processes; otherwise, there will be an expensive and time-consuming process to re-enter or convert information into the required format.

- The project information handover plan must be driven by the facility life cycle information strategy.

- The project information handover plan must be established early on before significant amounts of information are created.

- The implementation of the project information handover plan must be monitored to ensure that all parties are complying with the agreed information forms, formats, quality process and exchange methods.

Three major follow-on activities are recommended to help capital facilities industry move toward greater internal and external data readiness:

1. Associations in each capital industry sector (process, general building, transportation, and so forth) should participate in identifying best practices in information handover for their sector, particularly in terms of data forms and formats. They should document and communicate this information via sector-specific Parts 2 of this Capital Facilities Information Handover Guide.

2. The global capital facilities industry must join forces to overcome business obstacles to integrated work and information flows. These include contract, liability and insurance barriers. The capital facilities industry must restructure. Owners play a critical role in motivating this restructuring. One project delivery concept, which has shown to improve digital information use, is known as a project alliance. This approach is characterized by:

- A no-blame, no disputes culture

- Trust and alignment of objectives across all participants

- A risk/ reward philosophy to share losses and profits appropriately

- Identification of risks, with allocation of responsibility for them

- Transparent accountability, including detailed performance or outcome metrics, with financial incentives, linked to measurable goals, for all parties

- Team development, based on best-for-job resource allocation and efficient use of expertise

- Communication and quality training

- Regular reviews of strategic directions and performance.

- A project alliance-type arrangement for the London Heathrow Terminal 5 project has yielded very positive results.

3. Industry sectors and professional organizations should investigate organizational structures and business practices, including procurement practices, and regulatory, insurance and contractual requirements, which present obstacles to integrated work and information flows. These results should be used to define optimized value streams, work practices and project delivery. 


\section{APPENDICES}

\subsection{APPENDIX A - Glossary}

3-D: Three Dimensional

Ad hoc Standards: Formats that may have originated with a single vendor but have been made publicly available and are supported by multiple vendors and products.

Administrative Metadata: Metadata used to manage the information and includes such fields as: intellectual property status, file format, file size, creating system, archiving date, archiving expiration date and archiving refresh interval

$\boldsymbol{A E}$ : Architecture/ Engineering

AEC: Architecture/ Engineering/ Construction

AEX: Automating Equipment Information Exchange

AIA: American Institute of Architects

AISC: American Institute of Steel Construction

AP: Application Protocols

Avoidance costs: Costs incurred to prevent or minimize the impact of technical interoperability problems.

BLIS: Building Life Cycle Interoperable Software

CAD: Computer-aided Design

CAE: Computer-aided Engineering

CCITT: Comite Consultatif International Telephonique at Telegraphique (now ITU)

CFIHG: Capital Facilities Information Handover Guide

CII: Construction Industry Institute

CIM: Canadian Institute of Mining, Metallurgy and Petroleum

CIMSTEEL: Computer Integrated Manufacturing of Constructional Steelwork

CIS/2: CIMSteel Integration Standards Release 2

CMMS: Computerized Maintenance Management Systems

CNC: Computerized Numerical Control

Configuration Control: Information that moves through a protect and its status changes. For example a drawing may start as "issued for comment"; change to "issue for construction" and be updated to "As built”.

Continuous Commissioning: Process whereby the information requirements of the commissioning phase are considered from the moment of project conception and are captured and documented every step along the way

CURT: Construction Users Roundtable

Delay costs: Costs incurred when interoperability problems delay completion of a project or the length of time a facility is not in normal operation.

Descriptive Metadata: Metadata that identify and describe the information with fields such as creator, title, subject matter, responsible organization

DOE: Department of Energy 
DXF: Data Exchange File

EAM: Enterprise Asset Management

EAMS: Enterprise Asset Management Systems

EDI: Electronic Data Interchange

E-Handovers: Electronic handover of information and data

EPISTLE: European Process Industries Step Technical Liaison Executive

FEMP: Federal Energy Management Program

Formal Standards: Standards maintained by an official standards organization, such as ISO or ITU.

GCR: Governance Resource Center

GSA: General Services Administration

HVAC: Heating, Ventilating and Air-Conditioning

IAI: International Alliance for Interoperability

IFC: Industry Foundations Classes - Data elements that represent the parts of buildings or elements of the process, and contain the relevant information about those parts. IFCs are used by computer applications to assemble a computer readable model of the facility that contains all the information of the parts and their relationships to be shared among project participants.

IGES: Initial Graphics Exchange Specification

Interoperability: Ability to manage and communicate electronic product and project data between collaborating firms and within individual companies' design, construction, maintenance, and business process systems.

ISO: International Organization for Standardization

ITU: (Formerly CCITT). International Telecommunications Union. Committee of the United Nations that makes sure all telecommunications devices (like telephones, fax machines, modems and so on) can talk to each other, no matter what company makes them or in what country they're used.

JPEG: Joint Photographic Experts Group

Metadata: Metadata is a component of data which describes the data. It is "data about data."

Mitigation costs: Costs of activities responding to interoperability problems, including scrapped materials costs.

NAVFAC: Naval Facilities Engineering Command

NIBS: National Institute of Building Sciences

NIST: National Institute of Standards and Technology

OASIS: Open Archival Information System

OCR: Optical character recognition.

OLE: Object Linking Embedding

OOs: Owners and operators.

$\boldsymbol{O} \& \mathbf{M}, \boldsymbol{O M}$ : Operations and Maintenance

OSCRE: Open Standards Consortium for Real Estate

OMSI: Operations and Maintenance Support Information

PAS: Publicly Available Specification

PDF: Portable Document Format 
REIT: Real Estate Investment Trusts

STEP: Standard for the Exchange of Product Model Data

Structural Metadata: Metadata that describe the internal structure of the information and relationships between its components

Structured information form: Data in a structured form are machine-interpretable without human intervention.

TIFF: Tallied Image File Format

Unstructured Information: Data that cannot be machine interpreted.

USPI-NL: Uitgebreid Samenwerkingsverband Procesindustrie Nederland (Dutch Process and Power Industry Association).

$\boldsymbol{X}$-engineering: Art and science of using technology-enabled processes to connect businesses and companies with their customers to achieve dramatic improvements in efficiency and create value for everyone involved.

XML: Extensible Markup Language 


\subsection{APPENDIX B - Survey Forms}

Appendix B presents the survey instruments used to collect cost data for NIST GCR 04-867 Cost analysis of Inadequate Interoperability in the U.S. Capital Facilities Industry. These survey instruments are provided here to assist AECO Organizations in determining their costs.

B-1 Owners and Operators Survey Instrument

B-2 General Contractors Survey Instrument

B-3 Specialty Fabricators and Suppliers Survey Instrument

B-4 Architects and Engineers Survey Instrument

B-5CAD/CAM/CAE/PDM/ERP Software Vendors Survey Instrument 


\section{B-1. Owners and Operators Survey Instrument}

On behalf of the National Institute of Standards and Technology's (NIST's) Advanced Technology Program (ATP) and Building and Fire Research Laboratory (BFRL), RTI International and Logistics Management Institute (LMI) are conducting a cost analysis of inadequate interoperability in information exchange and management in the capital facilities industry. The goal of the study is to quantify the cost of inefficient information management and data exchange on industry stakeholders, including owners, architects, engineers, constructors, and suppliers involved in the life cycle of commercial, institutional, and industrial facilities.

Examples of these costs include those arising from the software maintenance expenses and labor associated with multiple design systems, the value of manpower required for data translation or reentry, redundant paper and software systems, and investment in third-party interoperability solutions.

Costs may also be generated through design corrections and revisions due to use of incorrect information; the value of manpower expended in the search for, and provision and validation of, redundant paper-based information; and information-access-related project delays.

As a member of the capital facilities supply chain, you have unique insights into the issues associated with inadequate interoperability in the capital facilities life cycle. The information you provide will enable NIST BFRL and industry to identify the impact of inadequate interoperability and plan future research and development efforts in the realm of interoperability.

Please use your experience in the capital facilities industry to answer this brief questionnaire. In addition, please feel free to collaborate with colleagues in your organization to answer the questions. We anticipate that the survey will take approximately 20 to 30 minutes to complete. 


\section{Respondent Identification}

Company Name:

Mailing Address:

Contact Name:

Title:

Phone Number:

E-mail:

Is the information in this questionnaire specific to your division, or is it for the entire company or governmental agency?

Division $\quad \square \quad$ Company/Agency

[Hereafter your company, division, or agency will be referred to as your "organization."]

Approximately how many employees are in your organization?

Employees

What are your organization's capital facilities life-cycle management responsibilities?

\section{Capital Facilities Stock Under Construction and Management}

These questions ask you to provide some measure of the scale of your organization's average annual capital facilities management activities. This information will allow us to aggregate your responses with those of other organizations.

2.1 In a typical year, in approximately how many new capital facilities projects is your organization engaged?

Projects

2.2 In a typical year, approximately how many total square feet do the above new commercial, institutional, and industrial projects represent (excluding petrochemical and utility plants)?

Square feet

2.3 What is the distribution of those new projects across facility types, by square footage?

\begin{tabular}{|l|l|l|}
\hline Commercial (e.g., office and/or large-scale residential buildings) & & Percent \\
\hline Institutional (e.g., schools and hospitals) & & Percent \\
\hline $\begin{array}{l}\text { Industrial (e.g., manufacturing establishments, except petrochemical } \\
\text { facilities and utilities) }\end{array}$ & & Percent \\
\hline Total & $100 \%$ & \\
\hline
\end{tabular}


2.4 What is your organization's current stock of capital facilities? Please complete the table below using your best estimates of the number and size of your existing facilities and the share of your organizations management activity required by each facility category.

\begin{tabular}{|l|l|l|l|l|}
\hline & $\begin{array}{l}\text { Share of Your } \\
\text { Organization's } \\
\text { Management } \\
\text { Activities (by } \\
\text { Labor Hours) }\end{array}$ & $\begin{array}{l}\text { Approximate } \\
\text { Number of } \\
\text { Facilities }\end{array}$ & $\begin{array}{l}\text { Estimated } \\
\text { Total Size of } \\
\text { Facilities }\end{array}$ & Unit \\
\hline Commercial & & & & Square feet \\
\hline Institutional & & & & Square feet \\
\hline $\begin{array}{l}\text { Industrial (excluding } \\
\text { petrochemical and utility } \\
\text { plants) }\end{array}$ & & & & Square feet \\
\hline Total & $100 \%$ & & & \\
\hline
\end{tabular}

\section{Design and Construction Life-Cycle Phases}

This section explores activities and investments related to information management and exchange during the design, engineering, and construction of capital facilities. These activities also include renovations, modifications, and/or additions to existing facilities.

\subsection{CAD/CAM/CAE (CAx) Software Systems}

What computer-aided design and engineering systems does your organization use? Please indicate the number of licenses (seats) you have for each system. Please also indicate whether each system is a primary, "in-house" system or a secondary system maintained for coordinating with external parties. A comments field is also provided should you wish to comment on your organization's use of each system. 


\begin{tabular}{|l|l|l|l|}
\hline CAx System Name & $\begin{array}{c}\text { Number of } \\
\text { Licenses } \\
\text { (or Seats) }\end{array}$ & $\begin{array}{c}\text { Is this a preferred } \\
\text { in-house (primary) } \\
\text { system? }\end{array}$ & Comments \\
\hline \hline & & $\square$ Yes $\square$ No & \\
\hline & & $\square$ Yes $\square$ No & \\
\hline & $\square$ Yes $\square$ No & \\
\hline & $\square$ Yes $\square$ No & \\
\hline & & $\square$ Yes $\square$ No & \\
\hline & $\square$ Yes $\square$ No & \\
\hline & & $\square$ Yes $\square$ No & \\
\hline & & $\square$ Yes $\square$ No & \\
\hline
\end{tabular}

The next three questions request the number of employees in your organization who use the CAx software systems listed in the table above. This questionnaire refers to those employees as "CAx users.”

3.1.1 How many CAx users are on staff at your organization?

Users

3.1.2 If applicable, what percentage of CAx users use systems that have duplicate capability (i.e., systems that are functional equivalents)?

Percent

3.1.3 Of these users, what is the average amount of time they spend using secondary systems that duplicate the primary system's capability?

Percent

\subsection{Interoperability Problems During Design and Construction}

This section asks you to reflect on the impact interoperability problems have on your organization's work load during the first two life-cycle phases. The first subsection asks about activities that occur prior to commencing construction. The second subsection asks questions about activities undertaken during the construction phase. Some questions are repeated in both Sections 3.2.1 and 3.2.2; it is important to respond to each question according to activities occurring during the specified time frame only. 


\subsubsection{Interoperability Problems Before Construction Begins}

3.2.1.1 Are the responses to this section to be provided on an annual basis for all projects or for an average project?
All projects
Per project

\subsubsection{Manual Reentry}

a. Do your employees ever manually reenter information from paper-based design and engineering planning information sources into your in-house electronic systems?

$\square$ No

$\square \quad$ Yes, requiring about man-hours per month

b. Do your employees ever manually transfer information from paper-based design and engineering planning information sources into your in-house paper-based systems?

\section{$\square$ No}

$\square$ Yes, requiring about man-hours per month

c. Do your employees ever manually reenter information from electronic design and engineering planning information sources into your in-house electronic systems?

No

Yes, requiring about

man-hours per month

3.2.1.3 Do employees require a measurable amount of time to verify that they are reviewing the correct version of either electronic files or paper designs?

No

Yes, requiring about man-hours per month

3.2.1.4 Managing Requests for Information (RFIs)

a. How many RFIs does your organization make before construction commences on an average project annually?

RFIs

b. How many man-hours are required to assemble and execute each RFI, on average?

Man-hours

c. How long does it take, on average, to receive a satisfactory

Business response to an RFI?

days

\subsubsection{Interoperability Problems During Construction}




\subsubsection{Manual Reentry}

a. Do your employees ever manually reenter as-built information from paper-based design and engineering planning changes into your electronic systems?

$$
\begin{array}{ll}
\square \quad \text { No } \\
\square \quad \text { Yes, requiring about }
\end{array}
$$

man-hours per month

b. Do your employees ever manually transfer as-built information from paper-based design and engineering planning changes into your paper-based systems?

$\square$ No

$\square$ Yes, requiring about man-hours per month

c. Do your employees ever manually reenter as-built information from as-built electronic design and engineering planning information sources into your electronic systems?

$\square$ No

$\square$ Yes, requiring about man-hours per month

3.2.2.2 Do employees require a measurable amount of time to verify that they are reviewing the correct version of either electronic files or paper designs?

No

Yes, requiring about man-hours per month

\subsubsection{Managing RFIs}

a. How many RFIs does your organization make after construction commences on an average project annually?

RFIs

b. How many man-hours are required to assemble and execute each RFI, on average? Man-hours

c. How long does it take, on average, to receive a Business satisfactory response to an RFI? days

\section{Operations and Maintenance Phase}

This section explores activities and investments related to information management and exchange during the operations and maintenance phase of capital facilities. These questions are specifically related to the facilities management process during this phase. 
4.1 In what format is most capital facilities information maintained at your organization? Please also estimate the percentage of facilities management information housed in each format. Note: "Preferred Systems" are the in-house systems that you listed in Question 3.1.

\begin{tabular}{|l|c|l|}
\hline \multicolumn{1}{|c|}{ File Format } & $\begin{array}{c}\text { Percentage of Total } \\
\text { Facilities } \\
\text { Information }\end{array}$ & Comment \\
\hline Paper Files & & \\
\hline $\begin{array}{l}\text { Preferred System(s) } \\
\text { Electronic Files }\end{array}$ & & \\
\hline $\begin{array}{l}\text { Miscellaneous } \\
\text { Electronic Files }\end{array}$ & & \\
\hline Total & $100 \%$ & \\
\hline
\end{tabular}

\subsection{Facilities Management Software Systems and Users}

4.2.1 Which software systems, if any, does your organization use to manage its capital facilities?

\begin{tabular}{|c|l|l|l|}
\hline $\begin{array}{c}\text { Software System } \\
\text { Name }\end{array}$ & $\begin{array}{c}\text { Number of } \\
\text { Licenses } \\
\text { (or Seats) }\end{array}$ & $\begin{array}{c}\text { Is This a } \\
\text { Preferred In- } \\
\text { House (primary) } \\
\text { System? }\end{array}$ & Comments \\
\hline \hline & & $\square$ Yes $\square$ No & \\
\hline & & $\square$ Yes $\square$ No & \\
\hline & $\square$ Yes $\square$ No & \\
\hline & $\square$ Yes $\square$ No & \\
\hline & & $\square$ Yes $\square$ No & \\
\hline
\end{tabular}

4.2.2 Facilities Management Software Systems Users

4.2.2.1 How many users on staff at your organization use the systems listed in Question 5.2.1?

Users

4.2.2.2 If applicable, what percentage of those users use systems that have duplicate capability?

Percent

4.2.2.3 Of these users, what is the average amount of time they spend using secondary systems that duplicate the primary system's capability? 


\subsection{Facilities Management Staff}

The following questions request some information about your facilities management engineers and employees and the amount of time they spend searching for, retrieving, and validating information.

4.3.1 How many operations and maintenance engineers are on staff at your organization?

Employees

4.3.2 What percentage of these operations and maintenance engineers' time is spent searching for and validating design and engineering plan paper archives?

Percent

4.3.3 What percentage of these operations and maintenance engineers' time is spent accessing legacy and miscellaneous electronic files and making them readable by in-house systems?

Percent

4.3.4 What percentage of these operations and maintenance engineers' time is spent waiting for others to provide them with the information needed to perform operations and maintenance tasks?

Percent

4.3.5 If these operations and maintenance engineers had access to that information electronically when they needed it, by what percentage do you estimate their time spent searching for and validating information from paper archives could be reduced?

Percent

4.4 In a typical year, are there incidences when operations and maintenance activities are reperformed because employees were proceeding with the incorrect version of the paper or electronic design and/or engineering files?

$\square$ No

Occurring about number of times per year

Requiring about man-hours per incident

Scrapping about dollars' worth of materials per incident

\section{Delay Costs Associated with Interoperability Problems and Efforts to Reduce the Occurrence of Those Problems}

5.1 In general, what types of delays has your organization experienced because of interoperability problems? What types of costs were associated with those delays? 
5.2 These questions ask about your organization's investments in data translation systems to reduce the incidence of poor CAx file transfer. They also ask about your internal research and development activities to reduce interoperability problems, as well as participation in industry consortia aiming to improve interoperability.

5.2.1 If your organization uses data translators licensed from a third-party software vendor, what are the approximate total annual licensing fees associated with those translators?

Dollars

5.2.2 If your organization uses third-party data translation and interoperability solutions providers, what is the approximate annual cost of those services?

Dollars

5.2.3 Has your firm invested in internal research and development in data translation and interoperability solutions? If yes, approximately how many dollars and/or man-hours are devoted to that activity annually?

5.2.4 If your organization participates in industry consortia cooperating on interoperability issues, what is the approximate annual cost of participation?
Dollars and/or Man-hours

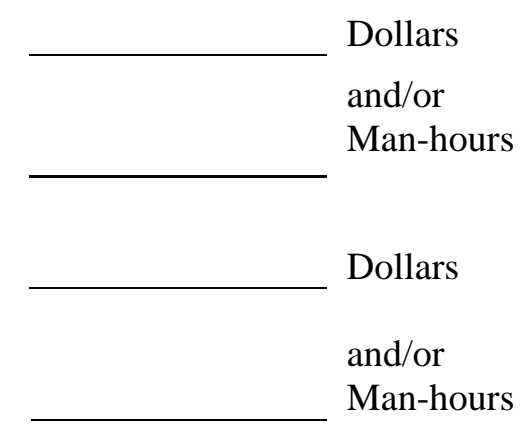

\section{Business Process Systems}

This section asks about the manpower employed in supporting the business systems that are used through out the capital facilities life cycle supply chain. To simplify responding to this section, the question is presented in table form. For each business process, please indicate whether your organization uses a software system to manage that process. Please also provide the number of fulltime equivalent (FTE) employees engaged in that activity. Finally, estimate the approximate reduction in labor effort that could be achieved if information management systems were fully electronic and interoperable internally and externally with clients and teaming partners.

\begin{tabular}{|c|c|c|c|}
\hline Business Process & $\begin{array}{c}\text { Dedicated } \\
\text { Software System } \\
\text { Used? }\end{array}$ & $\begin{array}{c}\text { Approximate } \\
\text { Number of FTEs } \\
\text { Engaged in This } \\
\text { Activity }\end{array}$ & $\begin{array}{c}\text { Percentage Labor } \\
\text { Reduction That } \\
\text { Could Be } \\
\text { Achieved If } \\
\text { Process Were } \\
\text { Fully Electronic } \\
\text { and/or } \\
\text { Interoperable }\end{array}$ \\
\hline Cost Estimation & $\square$ Yes $\square$ No & & \\
\hline Document Management & $\square$ Yes $\square$ No & & \\
\hline
\end{tabular}




\begin{tabular}{|l|l|l|l|}
\hline Enterprise Resource Planning & $\square$ Yes $\square$ No & & \\
\hline Facility Planning and Scheduling & $\square$ Yes $\square$ No & & \\
\hline Facility Simulation & $\square$ Yes $\square$ No & & \\
\hline Information Requests & $\square$ Yes $\square$ No & & \\
\hline Inspection and Certification & $\square$ Yes $\square$ No & & \\
\hline Maintenance Planning and & $\square$ Yes $\square$ No & & \\
Management & $\square$ Yes $\square$ No & & \\
\hline Materials Management & $\square$ Yes $\square$ No & & \\
\hline Procurement & $\square$ Yes $\square$ No & & \\
\hline Product Data Management & $\square$ Yes $\square$ No & & \\
\hline Project Management & $\square$ Yes $\square$ No & & \\
\hline Start-up and Commissioning & & & \\
\hline
\end{tabular}

\section{Comments}

Would you like to share other comments about interoperability issues in the capital facilities supply chain? If so, please do so in the space below.

Are you available for further comment about interoperability issues in the capital facilities supply chain?

$\square$ Yes

$\square$ No

Please indicate below if you would like to receive a copy of the final report for this analysis. A PDF file will be emailed to you once it has been released by NIST BFRL.

Yes, please email me a copy

$\square$ No

\section{Thank you!}




\section{B-2. General Contractors Survey Instrument}

On behalf of the National Institute of Standards and Technology's (NIST's) Advanced Technology Program (ATP) and Building and Fire Research Laboratory (BFRL), RTI International and Logistics Management Institute (LMI) are conducting a cost analysis of inadequate interoperability in information exchange and management in the capital facilities industry. The goal of the study is to quantify the cost of inefficient information management and data exchange on industry stakeholders, including owners, architects, engineers, constructors, and suppliers involved in the life cycle of commercial, institutional, and industrial facilities.

Examples of these costs include those arising from the software maintenance expenses and labor associated with multiple design systems, the value of manpower required for data translation or reentry, redundant paper and software systems, and investment in third-party interoperability solutions.

Costs may also be generated through design corrections and revisions due to use of incorrect information; the value of manpower expended in the search for, and provision and validation of, redundant paper-based information; and information-access-related project delays.

As a member of the capital facilities supply chain, you have unique insights into the issues associated with inadequate interoperability in the capital facilities life cycle. The information you provide will enable NIST BFRL and industry to identify the impact of inadequate interoperability and plan future research and development efforts in the realm of interoperability.

Please use your experience in the capital facilities industry to answer this brief questionnaire. In addition, please feel free to collaborate with colleagues in your organization to answer the questions. We anticipate that the survey will take approximately 20 to 30 minutes to complete. 
1. Respondent Identification

Company Name:

Mailing Address:

Contact Name:

Title:

Phone Number:

E-mail:

Is the information in this questionnaire specific to your division, or is it for the entire company or governmental agency?
Division
Company/Agency

[Hereafter your company, division, or agency will be referred to as your "organization."]

Approximately how many employees are in your organization?

Employees

What are your organization's capital facilities life-cycle management responsibilities?

\section{Annual Capital Facilities Construction Activities}

These questions ask you to provide some measure of the scale of your organization's average annual capital facilities construction activities. This information will allow us to aggregate your response with those of other organizations. 
2.1 In a typical year, in approximately how many capital facilities projects is your organization engaged?

Projects

2.2 In a typical year, approximately how many total square feet do commercial, institutional, and industrial projects represent (excluding petrochemical and utility plants)?

In a typical year, what is the approximate total capacity of your petrochemical and utility projects? Please specify your unit of measure.

2.3 How long does it take to complete construction activities for a typical project, on average?

Months

2.4 What is the distribution of those projects across facility types, by square footage?

\begin{tabular}{|l|l|l|}
\hline Commercial (e.g., office and/or large-scale residential buildings) & & Percent \\
\hline Institutional (e.g., schools and hospitals) & & Percent \\
\hline $\begin{array}{l}\text { Industrial (e.g., manufacturing establishments, except petrochemical } \\
\text { facilities and utilities) }\end{array}$ & & Percent \\
\hline Total & $100 \%$ & \\
\hline
\end{tabular}

\section{Information Technology Systems and Support}

This section explores your organization's investments in and use of software systems to support your business relationships with clients and teaming partners.

\subsection{CAD/CAM/CAE (CAx) Systems}

What software systems, such as AutoCAD and MicroStation, does your organization use in its construction activities for capital facilities projects? Please also indicate if a system duplicates the capability of your preferred "in-house" system. For example, if AutoCAD is your preferred system, but your organization also maintains MicroStation, enter MicroStation under "CAx System Name" but also indicate MicroStation in the third column for your AutoCAD record. 


\begin{tabular}{|l|l|l|l|}
\hline CAx System Name & $\begin{array}{c}\text { Number of } \\
\text { Licenses } \\
\text { (or Seats) }\end{array}$ & $\begin{array}{c}\text { Maintained } \\
\text { Secondary System } \\
\text { with Comparable } \\
\text { Capability }\end{array}$ & Comments \\
\hline \hline & & & \\
\hline & & & \\
\hline & & & \\
\hline & & & \\
\hline & & & \\
\hline
\end{tabular}

The next three questions request the number of employees in your organization who use the CAx systems listed in Question 3.1. This questionnaire refers to those employees as "CAx users."

3.1.1 How many CAx users are on staff at your organization?

Users

3.1.2 If applicable, what percentage of CAx users use systems that have duplicate capability (i.e., systems that are functional equivalents)?

Percent

3.1.3 Of these users, what is the average amount of time they spend using secondary systems that duplicate the primary system's capability?

Percent

\subsection{Data Translation Systems and Interoperability Research}

These questions ask about your organization's investments in data translation systems to reduce the incidence of poor CAx file transfer. They also ask about your internal research and development activities to reduce interoperability problems, as well as participation in industry consortia aiming to improve interoperability.

3.2.1 If your organization uses data translators licensed from a thirdparty software vendor, what are the approximate total annual licensing fees associated with those translators?

Dollars

3.2.2 If your organization uses third-party data translation and interoperability solutions providers, what is the approximate annual cost of those services? 
3.2.3 Has your firm invested in internal research and development in data translation and interoperability solutions? If yes, approximately how many man-hours are devoted to that activity annually?

3.2.4 If your organization participates in industry consortia cooperating on interoperability issues, what is the approximate Dollars annual cost of membership and/or donated labor hours for and/or participation? Man-hours

\section{Interoperability Problems}

This section asks you to reflect on the impact interoperability problems have on your organization's work load. The first subsection asks about activities that occur prior to commencing construction. The second subsection asks questions about activities undertaken during the construction phase. Some questions are repeated in both Sections 4.1 and 4.2; it is important to respond to each question according to activities occurring during the specified time frame only.

\subsection{Interoperability Problems Before Construction Commences}

4.1.1 Are the responses to this section to be provided on an annual basis for all projects or for an average project?
All projects
$\square$ Per project

4.1.1.1 Do your employees ever manually reenter information from paper-based design and engineering planning information sources into your in-house electronic systems?

No

Yes, requiring about man-hours per month

4.1.1.2 Do your employees ever manually transfer information from paper-based design and engineering planning information sources into your in-house paper-based systems?

$\square$ No

$\square$ Yes, requiring about man-hours per month

4.1.1.3 Do your employees ever manually reenter information from electronic design and engineering planning information sources into your in-house electronic systems?

No

Yes, requiring about man-hours per month 
4.1.2 Do employees require a measurable amount of time to verify that they are working with the correct version of either electronic files or paper designs?

$\square \quad$ No

$\square \quad$ Yes, requiring about man-hours per month

4.1.3 Managing Requests for Information (RFIs)

4.1.3.1 How many RFIs does your organization make before construction commences on an average project annually?

RFIs

4.1.3.2 How many man-hours are required to assemble and execute each RFI, on average?

Man-hours

4.1.3.3 How long does it take, on average, to receive a satisfactory response to an RFI?

Business

days

\subsection{Interoperability Problems During Construction}

4.2.1 Do your employees ever manually reenter as-built information from paper-based design and engineering planning changes into electronic systems for delivery to teaming partners and owners?

$\square$ No

$\square \quad$ Yes, requiring about man-hours per month

4.2.2 Do your employees ever manually transfer as-built information from paper-based design and engineering planning changes into paper-based systems for delivery to teaming partners and owners?

$\square \quad$ No

$\square$ Yes, requiring about man-hours per month

4.2.3 Do your employees ever manually reenter as-built information from as-built electronic design and engineering planning information sources into electronic systems for delivery to teaming partners and owners?

No

Yes, requiring about

man-hours per month

4.2.4 Do employees require a measurable amount of time to verify that they are working with the correct version of either electronic files or paper designs?

No

$\square$ Yes, requiring about man-hours per month 
4.2.5 Managing Requests for Information (RFIs)

4.2.5.1 How many RFIs does your organization make after construction commences on an average project annually?

RFIs

4.2.5.2 How many man-hours are required to assemble and execute each RFI, on average?

Man-hours

4.2.5.3 How long does it take, on average, to receive a satisfactory response to an RFI?

Business

days

4.2.6 In a typical year, are there incidences when construction set in place has to be reworked because employees were proceeding with the incorrect version of the paper or electronic design and/or engineering files?

No

Yes

Occurring about

number of times per year

$\square$ Requiring about

man-hours per incident

$\square$ Scrapping about dollars' worth of materials per incident

\subsection{Interoperability Problems After Construction Ends}

4.3.1 Do employees perform redundant tasks in transferring information to owners and operators after construction is completed, due to software systems that lack interoperability?

No

Yes, requiring about man-hours per month

\section{Impact of Delays Due to Interoperability Problems}

5.1 When construction-related activities are halted because of the submission of RFIs or other information-access related issues, are employees idle during this time?

$\square$ No

$\square$ Yes, idling about man-hours per month

5.2 If general contractors had access to all the information they needed when they needed it, would the average length of time required to complete a project be reduced?

$\square$ No
$\square$ Yes, about months or percent 
5.3 In general, what other types of delays has your organization experienced because of interoperability problems? What types of costs were associated with those delays?

\section{Business Process Systems}

This subsection asks whether your organization uses software systems to support certain business processes in the capital facilities supply chain. To simplify responding to this section, the question is presented in table form. For each business process, please indicate whether your organization uses a software system to facilitate information management. Please also provide the number of full-time equivalent (FTE) employees engaged in that process. Finally, estimate the approximate reduction in labor effort that could be achieved if information management systems were fully electronic and interoperable internally and with clients and teaming partners.

\begin{tabular}{|l|l|l|l|}
\hline \multicolumn{1}{|c|}{ Business Process } & \multicolumn{1}{c|}{$\begin{array}{c}\text { Pedicated } \\
\text { Software System } \\
\text { Used? }\end{array}$} & $\begin{array}{c}\text { Ape Labor } \\
\text { Reduction That } \\
\text { Could Be Achieved } \\
\text { If Process Were } \\
\text { Engaged in This } \\
\text { Activity }\end{array}$ & $\begin{array}{c}\text { Fully Electronic } \\
\text { and/or } \\
\text { Interoperable }\end{array}$ \\
\hline Accounting & $\square$ Yes $\square$ No & & \\
\hline Cost Estimation & $\square$ Yes $\square$ No & & \\
\hline Document Management & $\square$ Yes $\square$ No & & \\
\hline Enterprise Resource Planning & $\square$ Yes $\square$ No & & \\
\hline Facility Planning and Scheduling & $\square$ Yes $\square$ No & & \\
\hline Facility Simulation & $\square$ Yes $\square$ No & & \\
\hline Information Requests & $\square$ Yes $\square$ No & & \\
\hline Inspection and Certification & $\square$ Yes $\square$ No & & \\
\hline $\begin{array}{l}\text { Maintenance Planning } \\
\text { Management }\end{array}$ & $\square$ Yes $\square$ No & & \\
\hline Materials Management & $\square$ Yes $\square$ No & & \\
\hline Procurement & $\square$ Yes $\square$ No & & \\
\hline Product Data Management & $\square$ Yes $\square$ No & & \\
\hline Project Management & $\square$ Yes $\square$ No & & \\
\hline Start-up and Commissioning & $\square$ Yes $\square$ No & & \\
\hline
\end{tabular}




\section{Comments}

Would you like to share other comments about interoperability issues in the capital facilities supply chain? If so, please do so in the space below.

Are you available for further comment about interoperability issues in the capital facilities supply chain?

$\square$ Yes

$\square$ No

Please indicate below if you would like to receive a copy of the final report for this analysis. A PDF file will be emailed to you once it has been released by NIST BFRL.

$\square$ Yes, please email me a copy

$\square$ No

Thank you! 


\section{B-3. Specialty Fabricators and Suppliers Survey Instrument}

On behalf of the National Institute of Standards and Technology's (NIST's) Advanced Technology Program (ATP) and Building and Fire Research Laboratory (BFRL), RTI International and Logistics Management Institute (LMI) are conducting a cost analysis of inadequate interoperability in information exchange and management in the capital facilities industry. The goal of the study is to quantify the cost of inefficient information management and data exchange on industry stakeholders, including owners, architects, engineers, constructors, and suppliers involved in the life cycle of commercial, institutional, and industrial facilities.

Examples of these costs include those arising from the software maintenance expenses and labor associated with multiple design systems, the value of manpower required for data translation or reentry, redundant paper and software systems, and investment in third-party interoperability solutions.

Costs may also be generated through design corrections and revisions due to use of incorrect information; the value of manpower expended in the search for, and provision and validation of, redundant paper-based information; and information-access-related project delays.

As a member of the capital facilities supply chain, you have unique insights into the issues associated with inadequate interoperability in the capital facilities life cycle. The information you provide will enable NIST BFRL and industry to identify the impact of inadequate interoperability and plan future research and development efforts in the realm of interoperability.

Please use your experience in the capital facilities industry to answer this brief questionnaire. In addition, please feel free to collaborate with colleagues in your organization to answer the questions. We anticipate that the survey will take approximately 20 to 30 minutes to complete. 


\section{Respondent Identification}

Company Name:

Mailing Address:

Contact Name:

Title:

Phone Number:

E-mail:

Is the information in this questionnaire specific to your division, or is it for the entire company or governmental agency?
$\square$ Division
$\square$ Company/Agency

[Hereafter your company, division, or agency will be referred to as your "organization.”]

Approximately how many employees are in your organization?

Employees

What are your organization's capital facilities life-cycle management responsibilities? 


\section{Annual Capital Facilities Specialty and Fabrication and Supply Activities}

These questions ask you to provide some measure of the scale of your organization's average annual capital facilities fabrication and supply activities. This information will allow us to aggregate your response with those of other organizations.

2.1 In a typical year, in approximately how many capital facilities projects is your organization engaged?

Projects

2.2 In a typical year, approximately how many total square feet do commercial, institutional, and industrial projects represent (excluding petrochemical and utility plants)?

Square feet

In a typical year, what is the approximate total capacity of your petrochemical and utility projects? Please specify your unit of measure.

2.3 What is the distribution of those projects across facility types, by square footage?

\begin{tabular}{|l|l|l|}
\hline Commercial (e.g., office and/or large-scale residential buildings) & & Percent \\
\hline Institutional (e.g., schools and hospitals) & & Percent \\
\hline $\begin{array}{l}\text { Industrial (e.g., manufacturing establishments, except petrochemical } \\
\text { facilities and utilities) }\end{array}$ & & Percent \\
\hline Total & $100 \%$ & \\
\hline
\end{tabular}

\section{Information Technology Systems and Support}

This section explores your organization's investments in and use of software systems, if any, to support your internal operations as well as your relationships with clients and teaming partners.

\subsection{CAD/CAM/CAE (CAx) Systems}

What software systems, such as AutoCAD and MicroStation, does your organization use in its specialty construction and fabrication activities for capital facilities projects? Please also indicate if a system duplicates the capability of your preferred "in-house” system. 


\begin{tabular}{|l|l|l|l|}
\hline CAx System Name & $\begin{array}{c}\text { Number of } \\
\text { Licenses } \\
\text { (or Seats) }\end{array}$ & $\begin{array}{c}\text { Maintained } \\
\text { Secondary System } \\
\text { with Comparable } \\
\text { Capability }\end{array}$ & Comments \\
\hline \hline & & & \\
\hline & & & \\
\hline & & & \\
\hline & & & \\
\hline
\end{tabular}

The next three questions request the number of employees in your organization who use the CAx systems listed in Question 3.1. This questionnaire refers to those employees as "CAx users."

3.1.1 How many employees use the systems indicated in the above table?

Users

3.1.2 If applicable, what percentage of CAx users use systems that have duplicate capability (i.e., systems that are functional equivalents)?

Percent

3.1.3 Of these users, what is the average amount of time they spend using secondary systems that duplicate the primary system's capability?

Percent

\subsection{Data Translation Systems and Interoperability Research}

These questions ask about your organization's investments in data translation systems to reduce the incidence of poor CAx file transfer. They also ask about your internal research and development activities to reduce interoperability problems, as well as participation in industry consortia aiming to improve interoperability.

3.2.1 If your organization uses data translators licensed from a thirdparty software vendor, what are the approximate total annual licensing fees associated with those translators?

Dollars

3.2.2 If your organization uses third-party data translation and interoperability solutions providers, what is the approximate annual cost of those services?

Dollars 
3.2.3 Has your firm invested in internal research and development in data translation and interoperability solutions? If yes, approximately how many man-hours are devoted to that activity annually?

Man-hours

3.2.4 If your organization participates in industry consortia cooperating on interoperability issues, what is the approximate annual cost of membership and/or donated labor hours for Dollars participation? and/or

\section{Interoperability Problems}

The questions in this section ask you to reflect on the impact interoperability problems have on your organization's work load. The first subsection asks about activities that occur prior to commencing construction. The second subsection asks questions about activities undertaken during the construction phase. Some questions are repeated in both Sections 4.1 and 4.2; it is important to respond to each question according to activities occurring during the specified time frame only.

\subsection{Interoperability Problems Before Construction}

4.1.1 Are the responses to this section to be provided on an annual basis for all projects or for an average project?
$\square$ Total
Per project

\subsubsection{Manual Reentry}

4.1.2.1 Do your employees ever manually reenter information from paper-based design and engineering planning information sources into your in-house electronic systems?

$\square \quad$ No
$\square \quad$ Yes, requiring about man-hours per month

4.1.2.2 Do your employees ever manually transfer information from paper-based design and engineering planning information sources into your in-house paper-based systems?

\section{No}

Yes, requiring about

man-hours per month

4.1.2.3 Do your employees ever manually reenter information from electronic design and engineering planning information sources into your in-house electronic systems?

No

$\square \quad$ Yes, requiring about man-hours per month 
4.1.3 Do employees require a measurable amount of time to verify that they are working with the correct version of either electronic files or paper designs?

No

$\square$ Yes, requiring about man-hours per month

4.1.4 Managing Requests for Information (RFIs)

4.1.4.1 How many RFIs does your organization make before construction commences on an average project annually?

RFIs

4.1.4.2 How many man-hours are required to assemble and execute each RFI, on average?

Man-hours

4.1.4.3 How long does it take, on average, to receive a satisfactory response to an RFI?

Business

days

\subsection{Interoperability Problems After Construction Commences}

4.2.1 Do your employees ever manually reenter as-built information from paper-based design and engineering planning changes into electronic systems for delivery to teaming partners and owners?

$\square$ No

$\square$ Yes, requiring about man-hours per month

4.2.2 Do your employees ever manually transfer as-built information from paper design and engineering planning changes into paper systems for delivery to teaming partners and owners?

\section{No}

Yes, requiring about man-hours per month

4.2.3 Do your employees ever manually reenter as-built information from as-built electronic design and engineering planning information sources into electronic systems for delivery to teaming partners and owners?

No

Yes, requiring about man-hours per month

4.2.4 Do employees require a measurable amount of time to verify that they are working with the correct version of either electronic files or paper designs?

No

Yes, requiring about man-hours per month

\subsubsection{Managing RFIs}


4.2.5.1 How many RFIs does your organization make after construction commences on an average project annually?

RFIs

4.2.5.2 How many man-hours are required to assemble and execute each RFI, on average?

Man-hours

4.2.5.3 How long does it take, on average, to receive a satisfactory response to an RFI?

Business days

4.2.6 In a typical year, are there incidences when construction set in place has to be reworked because employees were proceeding with the incorrect version of the paper or electronic design and/or engineering files?

\section{$\square \quad$ No \\ $\square \quad$ Yes}

$\square$ Occurring about

Requiring about

Scrapping about

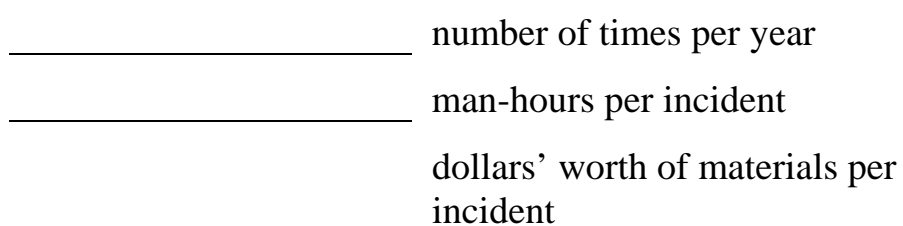
incident

\section{Impact of Delays Due to Interoperability Problems}

5.1 When construction-related activities are halted because of the submission of RFIs or other informationaccess related issues, are employees idle during this time?

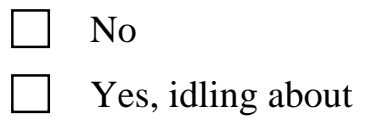
man-hours per month

5.2 If employees in your organization had access to all the information they needed when they needed it, would the average length of time required to construct a new facility be reduced?

No

$\square$ Yes, about months or percent

5.3 In general, what other types of delays has your organization experienced because of interoperability problems? What types of costs were associated with those delays? 


\section{Business Process Systems}

This section asks whether your organization uses software systems to support certain business processes in the capital facilities supply chain. To simplify responding to this section, the question is presented in table form. For each business process, please indicate whether your organization uses a software system to facilitate information management. Please also provide the number of full-time equivalent (FTE) employees engaged in that process. Finally, estimate the approximate reduction in labor effort that could be achieved if information management systems were fully electronic and interoperable internally and with clients and teaming partners.

\begin{tabular}{|c|c|c|c|c|}
\hline Business Process & $\begin{array}{r}\text { Ded } \\
\text { Softwa } \\
\mathrm{U}\end{array}$ & $\begin{array}{l}\text { ed } \\
\text { ystem }\end{array}$ & $\begin{array}{c}\text { Approximate } \\
\text { Number of FTEs } \\
\text { Engaged in This } \\
\text { Activity }\end{array}$ & $\begin{array}{c}\text { Percentage Labor } \\
\text { Reduction That } \\
\text { Could Be } \\
\text { Achieved If } \\
\text { Process Were } \\
\text { Fully Electronic } \\
\text { and/or } \\
\text { Interoperable }\end{array}$ \\
\hline Accounting & Yes & No & & \\
\hline Cost Estimation & Yes & No & & \\
\hline Document Management & Yes & No & & \\
\hline Enterprise Resource Planning & Yes & No & & \\
\hline Facility Planning and Scheduling & Yes & No & & \\
\hline Facility Simulation & Yes & No & & \\
\hline Information Requests & Yes & No & & \\
\hline Inspection and Certification & Yes & No & & \\
\hline $\begin{array}{lll}\begin{array}{l}\text { Maintenance } \\
\text { Management }\end{array} & \text { Planning } & \text { and } \\
\end{array}$ & Yes & No & & \\
\hline Materials Management & Yes & No & & \\
\hline Procurement & Yes & No & & \\
\hline Product Data Management & Yes & No & & \\
\hline Project Management & Yes & No & & \\
\hline Start-up and Commissioning & Yes & No & & \\
\hline
\end{tabular}

\section{Comments}

Would you like to share other comments about interoperability issues in the capital facilities supply chain? If so, please do so in the space below. 
Are you available for further comment about interoperability issues in the capital facilities supply chain?
$\square$ Yes
$\square$ No

Please indicate below if you would like to receive a copy of the final report for this analysis. A PDF file will be emailed to you once it has been released by NIST BFRL.

$\square$ Yes, please email me a copy

\section{Thank you!}




\section{B-4. Architects and Engineers Survey Instrument}

On behalf of the National Institute of Standards and Technology's (NIST's) Advanced Technology Program (ATP) and Building and Fire Research Laboratory (BFRL), RTI International and Logistics Management Institute (LMI) are conducting a cost analysis of inadequate interoperability in information exchange and management in the capital facilities industry. The goal of the study is to quantify the cost of inefficient information management and data exchange on industry stakeholders, including owners, architects, engineers, constructors, and suppliers involved in the life cycle of commercial, institutional, and industrial facilities.

Examples of these costs include those arising from the software maintenance expenses and labor associated with multiple design systems, the value of manpower required for data translation or reentry, redundant paper and software systems, and investment in third-party interoperability solutions.

Costs may also be generated through design corrections and revisions due to use of incorrect information; the value of manpower expended in the search for, and provision and validation of, redundant paper-based information; and information-access-related project delays.

As a member of the capital facilities supply chain, you have unique insights into the issues associated with inadequate interoperability in the capital facilities life cycle. The information you provide will enable NIST BFRL and industry to identify the impact of inadequate interoperability and plan future research and development efforts in the realm of interoperability.

Please use your experience in the capital facilities industry to answer this brief questionnaire. In addition, please feel free to collaborate with colleagues in your organization to answer the questions. We anticipate that the survey will take approximately 20 to 30 minutes to complete. 


\section{Respondent Identification}

Company Name:

Mailing Address:

Contact Name:

Title:

Phone Number:

E-mail:

Is the information in this questionnaire specific to your division, or is it for the entire company or governmental agency?
Division
Company/Agency

[Hereafter your company, division, or agency will be referred to as your "organization."]

Approximately how many employees are in your organization?

Employees

What are your organization's capital facilities life-cycle management responsibilities?

\section{Annual Design, Engineering, and Planning Activities}

These questions ask you to provide some measure of the scale of your organization's average annual design, engineering, and/or planning activities for capital facilities. This information will allow us to aggregate your response with those of other organizations. 
2.1 In a typical year, in approximately how many capital facilities projects is your organization engaged?

Projects

2.2 In a typical year, approximately how many total square feet do commercial, institutional, and industrial projects represent (excluding petrochemical and utility plants)?

Square feet

In a typical year, what is the approximate total capacity of year petrochemical and utility projects? Please specify your unit of measure.

2.3 What is the distribution of those projects across facility types, by square footage?

\begin{tabular}{|l|l|l|}
\hline Commercial (e.g., office and/or large-scale residential buildings) & & Percent \\
\hline Institutional (e.g., schools and hospitals) & & Percent \\
\hline $\begin{array}{l}\text { Industrial (e.g., manufacturing establishments, except petrochemical } \\
\text { facilities and utilities) }\end{array}$ & & Percent \\
\hline Total & $100 \%$ & \\
\hline
\end{tabular}

\section{Information Technology Systems and Support}

This section explores your organization's investments in and use of software systems, if any, to support your internal operations as well as your relationships with clients and teaming partners.

\subsection{CAD/CAM/CAE (CAx) Systems}

What CAx software systems, such as AutoCAD and MicroStation, does your organization use in its design and/or engineering work for capital facilities projects? Please also indicate if a system duplicates the capability of your preferred "in-house" system. For example, if AutoCAD is your preferred design system, but your organization also maintains MicroStation, enter MicroStation under “CAx System Name” but also indicate MicroStation in the third column for your AutoCAD record. 


\begin{tabular}{|l|l|l|l|}
\hline CAx System Name & $\begin{array}{c}\text { Number of } \\
\text { Licenses } \\
\text { (or Seats) }\end{array}$ & $\begin{array}{c}\text { Maintained } \\
\text { Secondary System } \\
\text { with Comparable } \\
\text { Capability }\end{array}$ & Comments \\
\hline \hline & & & \\
\hline & & & \\
\hline & & & \\
\hline & & & \\
\hline
\end{tabular}

The next three questions request the number of architects, designers, and engineers in your organization who use the CAx systems listed in Question 3.1. This questionnaire refers to those employees as "CAx users."

3.1.1 How many employees use the systems indicated in the above table?

Users

3.1.2 If applicable, what percentage of CAx users use systems that have duplicate capability (i.e., systems that are functional equivalents)?

Percent

3.1.3 Of these users, what is the average amount of time they spend using secondary systems that duplicate the primary system's capability?

Percent

\subsection{Data Translation Systems and Interoperability Research}

These questions ask about your organization's investments in data translation systems to reduce the incidence of poor CAx file transfer. They also ask about your internal research and development activities to reduce interoperability problems, as well as participation in industry consortia aiming to improve interoperability.

3.2.1 If your organization uses data translators licensed from a thirdparty software vendor, what are the approximate total annual licensing fees associated with those translators?

Dollars

3.2.2 If your organization uses third-party data translation and interoperability solutions providers, what is the approximate annual cost of those services? 
3.2.3 Has your firm invested in internal research and development in data translation and interoperability solutions? If yes, approximately how many man-hours are devoted to that activity annually?

3.2.4 If your organization participates in industry consortia cooperating on interoperability issues, what is the approximate annual cost of membership and/or donated labor hours for participation?

Dollars

and/or

Man-hours

\section{Interoperability Problems}

This section asks you to reflect on the impact interoperability problems have on your organization's work load. The first subsection asks about activities during the design, engineering, and planning phase of a new facility. The second subsection asks questions about activities undertaken during the construction phase (i.e., after the final design and engineering plans have been submitted, approved, and implemented). These questions are tailored specifically to your organization's employees tasked with performing facility design, engineering, and or planning work.

\subsection{Interoperability Problems Before Construction Commences}

4.1.1 Are the responses to this section to be provided on an annual basis for all projects or for an average project?
All projects
Per project

4.1.1.2 Do employees ever manually reenter information from paper-design changes and/or electronic design files into your electronic systems? This may occur as a result of alterations based on comments and design changes submitted by owner/operators and teaming partners or poor electronic file transfer.

$\square$ No

$\square$ Yes, requiring about man-hours per month

4.1.1.3 Do employees require a measurable amount of time to verify that they are working with the correct version of either electronic files or paper designs?

No

Yes, requiring about

man-hours per month 
4.1.2 In a typical year, are there incidences when designs and/or engineering plans have had to be reworked because employees were proceeding with the incorrect version of the paper or electronic files?

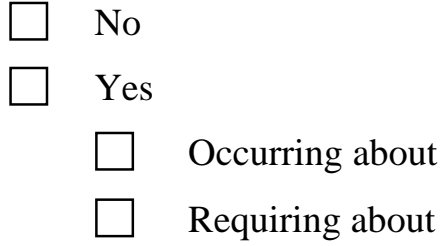
number of times per year hours of rework per incidence

\subsection{Interoperability Problems After Construction Commences}

4.2.1 Do employees ever manually reenter design changes from paper and/or electronic files from general contractors or owner/operators into your electronic systems after construction has commenced? This may occur because of alterations due to construction activity or submission of comments and design changes or poor electronic file transfer.

No

Yes, requiring about man-hours per month

4.2.2 Do employees require a measurable amount of time to verify that they are working with the correct version of either electronic files or paper designs?

No

Yes, requiring about man-hours per month

4.2.3 When managing requests for information (RFIs) from either general contractors or owner/operators, do employees spend a measurable amount of time transferring information into either a paper-based format or a new electronic file for delivery to requesting parties?

No

$\square \quad$ Yes, requiring about man-hours per month

\subsection{Interoperability Problems After Construction Ends}

4.3.1 Do employees perform redundant tasks in transferring information to owners and operators after construction is completed, due to software systems that lack interoperability?

\section{No}

Yes, requiring about man-hours per month

\section{Impact of Delays Due to Interoperability Problems}

In general, what types of delays has your organization experienced because of interoperability problems? What types of costs were associated with those delays? 


\section{Business Process Systems}

This section asks whether your organization uses software systems to support certain business processes. To simplify responding to this section, the question is presented in table form. For each business process, please indicate whether your organization uses a software system to facilitate information management. Please also provide the number of full-time equivalent (FTE) employees engaged in that process. Finally, estimate the approximate reduction in labor effort that could be achieved if information management systems were fully electronic and interoperable internally and with clients and teaming partners. 


\begin{tabular}{|l|l|l|l|}
\hline \multicolumn{1}{|c|}{ Business Process } & \multicolumn{1}{|c|}{$\begin{array}{c}\text { Percentage Labor } \\
\text { Reduction That } \\
\text { Could Be } \\
\text { Achieved If } \\
\text { Software System } \\
\text { Used? }\end{array}$} & $\begin{array}{c}\text { Process Were } \\
\text { Approximate } \\
\text { Engaged in This } \\
\text { Activity }\end{array}$ & $\begin{array}{c}\text { Fully Electronic } \\
\text { and/or } \\
\text { Interoperable }\end{array}$ \\
\hline Accounting & $\square$ Yes $\square$ No & & \\
\hline Cost Estimation & $\square$ Yes $\square$ No & & \\
\hline Document Management & $\square$ Yes $\square$ No & & \\
\hline Enterprise Resource Planning & $\square$ Yes $\square$ No & & \\
\hline Facility Planning and Scheduling & $\square$ Yes $\square$ No & & \\
\hline Facility Simulation & $\square$ Yes $\square$ No & & \\
\hline Information Requests & $\square$ Yes $\square$ No & & \\
\hline Materials Management & $\square$ Yes $\square$ No & & \\
\hline Procurement & $\square$ Yes $\square$ No & & \\
\hline Project Management & $\square$ Yes $\square$ No & & \\
\hline
\end{tabular}

\section{Comments}

Would you like to share other comments about interoperability issues in the capital facilities supply chain? If so, please do so in the space below.

Are you available for further comment about interoperability issues in the capital facilities supply chain?
$\square$ Yes
$\square$ No

Please indicate below if you would like to receive a copy of the final report for this analysis. A PDF file will be emailed to you once it has been released by NIST BFRL.

$\square$ Yes, please email me a copy

$\square$ No

\section{Thank you!}




\section{B-5. CAD/CAM/CAE/PDM/ERP Software Vendors Survey Instrument}

On behalf of the National Institute of Standards and Technology's (NIST's) Advanced Technology Program (ATP) and Building and Fire Research Laboratory (BFRL), RTI International and Logistics Management Institute (LMI) are conducting a cost analysis of inadequate interoperability in information exchange and management in the capital facilities industry. The goal of the study is to quantify the cost of inefficient information management and data exchange on industry stakeholders, including owners, architects, engineers, constructors, and suppliers involved in the life cycle of commercial, institutional, and industrial facilities.

NIST BFRL's aim is to measure the cost associated with the inadequate interoperability in both information exchange and management. Examples of these costs include those arising from the purchase and labor associated with the value of labor lost due to data translation or reentry, redundant paper systems, and investment in third-party interoperability solutions. Such costs may also be generated through design changes due to initial use of incorrect information; value of labor lost in the search for, provision, and validation of redundant paper-based information; and information-accessrelated project delays.

As a member of the industry that produces the software used in the design, engineering, and facilities management operations of the industry we are investigating, you have unique insights into the state of intersystem connectivity of CAD, CAM, CAE, PDM, and/or ERP software. The information you provide will help NIST better assess the costs of inadequate interoperability and the research and development needs, thereby allowing NIST to channel future investments toward projects that best meet those needs.

Please answer the questions in the attached questionnaire with reference to your CAD, CAM, CAE, PDM, or ERP software products. In addition, please feel free to collaborate with colleagues in answering the questions. The information you provide is confidential and will only be used in aggregate with responses from other companies in the industry. Your individual response will not be disclosed to any third party, including NIST. 


\section{Company Identification}

Company Name:

Mailing Address:

Contact Name:

Title:

Phone Number:

E-mail:

\section{CAD/CAM/CAE/PDM/ERP Product information}

2.1 Please list your company's CAD, CAM, CAE, PDM, or ERP software packages and specialty products below that are used by the capital facilities industry (i.e., for the design and engineering, and facilities management of commercial, institutional, and industrial buildings).

2.2 Do the CAD, CAM, CAE, PDM, or ERP software programs your firm markets currently offer any neutral format or intersystem functionality, or will they in the near future?

$\square$ Yes. In which year(s) did or will these programs first include neutral file format capability and/or intersystem connectivity?

\section{No. (End survey)}

2.3 Which neutral file formats do your software systems currently support? 
2.4 With which systems are your software systems interoperable? Are these systems predominantly within your firm's product family or do they also have connectivity with other firms' offerings?

3. The Cost of Developing Neutral File Format Functionality or Intersystem Connectivity

3.1 Was your company involved in the administrative process to develop the standards for neutral file format functionality or intersystem connectivity, in developing new technologies and tools, or in supporting demonstrations or certification testing?

$\square$ Yes. Over what time frame did you participate and what were your approximate annual expenditures in terms of person-months?

\begin{tabular}{|l|l|l|}
\hline \multicolumn{1}{|c|}{ Activities } & $\begin{array}{c}\text { Time Period Involved } \\
\text { (Example: 1995 to } \\
\text { 2001) }\end{array}$ & $\begin{array}{c}\text { Average Annual } \\
\text { Expenditures } \\
\text { (person-months/year) }\end{array}$ \\
\hline $\begin{array}{l}\text { Standards development process } \\
\text { (Example: Attended meeting or reviewed } \\
\text { draft standards) }\end{array}$ & & \\
\hline $\begin{array}{l}\text { Software development tools and testing } \\
\text { tools } \\
\text { (Example: } \text { Supported the development of } \\
\text { languages or libraries) }\end{array}$ & & \\
\hline $\begin{array}{l}\text { Demonstration and certification services } \\
\text { (Example: Participated in the AutoSTEP } \\
\text { project or other implementation forums) }\end{array}$ & & \\
\hline
\end{tabular}

No. Our company was not involved in these activities. 
3.2 What were your company's total expenditures to integrate neutral file formats and/or develop intersystem connectivity into your CAD, CAM, CAE, PDM, or ERP systems? (Choose one)

Dollars

or

Labor (person-months)

\section{Comments}

4.1 Please provide any additional comments that would help us evaluate the cost of integrating neutral file format and/or intersystem connectivity into your CAD, CAM, CAE, PDM, or ERP software products.

Thank you for your participation. 


\subsection{APPENDIX C - Bibliography}

American Institute of Architects (AIA) Interim Report. A Response to "Collaboration, Integrated Information and the Project Lifecycle in Building Design, Construction and Operation” (WP-1202): A Report of the Construction Users Roundtable (CURT).2004.

American Institute of Architects (AIA) Technology in Architectural Practice Knowledge Community. Building Connections. Internet. http://www.building-connections.info. Accessed 20 April 2005.

Champy, James. X-Engineering the Corporation: Reinventing Your Business in the Digital Age. New York: Warner Business Books, 2002.

Construction Cost Effectiveness Task Force, The Business Roundtable. The Business Stake in Effective Project Systems. 1997. http://www.curt.org/pdf/104.pdf.

Construction Industry Council (CIC). A Guide to Project Team Partnering. 2002.

Construction Industry Institute. Alignment during Pre-Project Planning - A Key to Project Success. 1997. Implementation Resource 113-3.

Construction Industry Institute. Best Practices Guide for improving Project Performance. 2002. Implementation Resource 166-3.

Construction Industry Institute. Constructability Implementation Guide. Bureau of Engineering Research. Austin: The University of Texas, 2002. Publication 34-2.

Construction Industry Institute. RS106-1: 3D CAD Link. 1995.

Construction Industry Institute. Pre-Project Planning Handbook. 1995. Special Publication 39-2.

Construction Industry Institute. Project Definition Rating Index Industrial Projects. 1996. Implementation Resource 113-2.

Construction Industry Institute. Planning for Start Up. 1998. Implementation Resource 121-2.

Construction Users Roundtable (CURT) Architectural/ Engineering Productivity Committee. Collaboration, Integrated Information and the Project Life Cycle in Building Design, Construction and Operation (WP-1202). 2004.

Construction Task Force, Department of the Environment, Transport and the Regions. Rethinking Construction. London: DETR Publications, 1998.

Department of the Navy. Naval Facilities Engineering Command (NAVFAC). 2000. Operations and Maintenance Support Information (OMSI) for Facility Projects. Internet. http://www.navfac.navy.mil/doclib/files/11013_39.pdf. Accessed 24 May 2005.

Dutch Process and Power Industry Association. Reaching the Process Industry Vision: Roadmap to Competitive Advantage Via Sharing and Storing Plant Life Cycle Data. Netherlands: Amersfoort, 2002.

FIATECH. Element 9: Lifecycle Data Management \& Information Integration. In Capital Projects Technology Roadmap. 2004. http://www.fiatech.org/projects/roadmap/workforce.html.

Gallaher, Michael P., Alan C. O’Connor, John L. Dettbarn Jr. and Linda T. Gilday. National Institute 
of Standards and Technology (NIST). Cost Analysis of Inadequate Interoperability in the U.S. Capital Facilities in the U.S. Capital Facilities Industry (GCR 04-867). 2004.

http://www.bfrl.nist.gov/oae/publications/gcrs/04867.pdf.

InfoWeb. Façade Example. Internet. http://www.infoweb.ws/cfihg_mapper. Accessed on 20 April 2005.

International Alliance for Interoperability. Industry Foundation Classes, IFC-2X Platform Specifications. 2003.

International Organization for Standardization. Open Archival Information System. Reference Model, ISO 14721:2003.

Open Standards Consortium for Real Estate. Internet. http://www.oscre.org. Accessed on 20 April 05.

RTI International and the Logistics Management Institute. NIST GCR 04-867. 2004. http://www.bfrl.nist.gov/oae/publications/gcrs/04867.pdf.

U.S. Census Bureau 2004b. Annual Value of Construction Set in Place. Washington D.C.

U.S. Department of Energy. Federal Energy Management Program. Model Commissioning Plan and Guide Specifications Version 2.05. 1998.

U.S. General Services Administration (GSA). Whole Building Design Guide. Internet. Available from http://www.wbdg.org/project/buildingcomm.php; accessed on 20 April 2005.

U.S. National Institute of Building Sciences. Total Building Commissioning Project. 1999. Internet. http://sustainable.state.fl.us/fdi/edesign/resource/totalbcx/guidemod/docs/01nov98.html. Accessed on 31 January 2005. 


\subsection{APPENDIX D - Links to information delivery specifications and standards}

2005 Code of Standard Practice for Steel Buildings and Bridges. 2005.

http://www.aisc.org/ContentManagement/ContentDisplay.cfm?ContentID=27714

Accessed on 18 May 2005.

CIMsteel Integration Standards, Release 2 (CIS/2), 2003.

http://www.cis2.org

Accessed on 18 May 2005.

EPISTLE Data Handover Guide, 1998.

http://www.uspi.nl/download_folders/standards/HandoverGuide_Part1.pdf

http://www.uspi.nl/download folders/standards/HandoverGuide Part2.pdf

Accessed on 18 May 2005.

European CIMSTEEL initiative (1987 - 1998),

http://www.civil.ubc.ca/ tfroese/rsch/models/directory/step_bc_core/appp1_940503.html

Accessed on 18 May 2005.

FIATECH's Automating Equipment Information Exchange (AEX): XML schemas for the exchange of equipment information, Version 1.0, 2004.

http://www.fiatech.org/pdfs/Resources/Contents.pdf

Accessed on 18 May 2005.

IGES (Initial Graphics Exchange Specification), 1996.

http://www.itl.nist.gov/fipspubs/fip177-1.htm

Accessed on 18 May 2005.

Industry Foundation Classes - Release 2x (IFC 2x), IFC Technical Guide, Enabling Interoperability in the AEC/ FM, 2000.

http://www.iai-international.org/Model/documentation/IFC 2x Technical_Guide.pdf

Accessed on 18 May 2005.

International Organization for Standardization (ISO) 10303 Standard for the Exchange of Product Model Data (STEP): Multi-part standard, Published and under development.

http://www.tc184-sc4.org/SC4_Open/SC4_Work_Products_Documents/STEP_(10303)

Accessed on 18 May 2005.

ISO (International Organization for Standardization) 10303-203 - Configuration-Controlled 3D

Design of Mechanical Parts and Assemblies, Published standard, 1996.

http://www.iso.org/iso/en/CatalogueDetailPage.CatalogueDetail?CSNUMBER=26904

Accessed on 18 May 2005.

ISO (International Organization for Standardization) 10303-221: Functional Data and their Schematic Representations for Process Plants, under development.

http://www.iso.org/iso/en/CatalogueDetailPage.CatalogueDetail?CSNUMBER=36771\&scopelist=PR OGRAMME

Accessed on 18 May 2005.

ISO (International Organization for Standardization) 10303-227: Plant Spatial Configuration.

Published standard, 2001.

http://www.iso.org/iso/en/CatalogueDetailPage.CatalogueDetail?CSNUMBER=25086

Accessed on 18 May 2005. 
ISO (International Organization for Standardization) 12006-2 provides a framework for the classification of information about construction works. implementations of 12006-2, particularly Uniclass in the U.K. and Omniclass in the U.S., Published Standard, 2001. http://www.iso.org/iso/en/CatalogueDetailPage.CatalogueDetail?CSNUMBER=35333\&ICS1=91\&IC $\underline{\mathrm{S} 2=10 \& \mathrm{ICS} 3=1}$

Acessed on 19 May 2005.

ISO (International Organization for Standardization) 14721: 2003 Defines an archival system dedicated to preserving and maintaining access to digital information over the long term, Published Standard, 2003.

http://www.iso.org/iso/en/CatalogueDetailPage.CatalogueDetail?CSNUMBER=24683\&ICS1=49\&IC $\underline{\mathrm{S} 2=140 \& \mathrm{ICS} 3}=$

Acessed on 19 May 2005.

ISO (International Organization for Standardization) 15926: Integration of Life-Cycle Data for Process Plants Including Oil and Gas Production, designed to provide a comprehensive standard for the description of process plant facilities

Part 1, Published Standard, 2004.

http://www.iso.org/iso/en/CatalogueDetailPage.CatalogueDetail?CSNUMBER=29556\&ICS1=75\&IC $\underline{\mathrm{S} 2=20 \& \mathrm{ICS} 3}=$

Part 2, Published Standard, 2003.

http://www.iso.org/iso/en/CatalogueDetailPage.CatalogueDetail?CSNUMBER=29557\&ICS1=25\&IC $\underline{\mathrm{S} 2=40 \& \mathrm{ICS} 3=40}$

Part 4, Under development

http://www.iso.org/iso/en/CatalogueDetailPage.CatalogueDetail?CSNUMBER=41329\&scopelist=PR OGRAMME

Accessed on 19 May 2005.

ISO/PAS (International Organization for Standardization/ Publicly Available Specification) 16739. This standard covers the general building type, Under development. http://www.iso.org/iso/en/CatalogueDetailPage.CatalogueDetail?CSNUMBER=38056\&scopelist=PR OGRAMME

Accessed on 18 May 2005.

ISO (International Organization for Standardization) 17799

Information technology -- Security techniques -- Code of practice for information security

management

Edition 1, Published standard, 2001.

http://www.iso.org/iso/en/CatalogueDetailPage.CatalogueDetail?CSNUMBER=33441\&ICS1=35\&IC $\underline{\mathrm{S} 2=40 \& \mathrm{ICS} 3}=$

Edition 2, Under development.

http://www.iso.org/iso/en/CatalogueDetailPage.CatalogueDetail?CSNUMBER=39612\&scopelist=PR OGRAMME

Accessed on 19 May 2005.

ISO/DIS (International Organization for Standardization) 82045.5 Document management - Part 5: Application of metadata for the construction and facility management sector (2004-03-11).

Part 5 Under development.

http://www.iso.org/iso/en/CatalogueDetailPage.CatalogueDetail?CSNUMBER=34952\&scopelist=PR OGRAMME

Accessed on 19 May 2005. 


\title{
Organizations that Promote Interoperability
}

\author{
AISC - American Institute of Steel Construction \\ www.aisc.org \\ BLIS - Building Lifecycle Interoperable Software \\ www.blis-project.org \\ Building Connections \\ www.building-connections.info \\ CABA - Continental Automated Buildings Association \\ www.caba.org \\ CURT - Construction Users Roundtable \\ www.curt.org \\ FIATECH \\ www.fiatech.org \\ gbXML - Green Building XML \\ www.gbxml.org \\ IAI - International Alliance for Interoperability \\ www.iai-na.org \\ IFMA - International Facility Management Association \\ www.ifma.org
}

MIMOSA - Machinery Information Management Open Systems Alliance www.mimosa.org

NFRC - National Fenestration Rating Council www.nfrc.org

NIBS - National Institute of Building Sciences www.nibs.org

NIST - National Institute of Standards and Technology cic.nist.gov

OSCRE - Open Standards Consortium for Real Estate www.oscre.org

PISCES - Property Information Systems Common Exchange Standard Limited www.pisces.co.uk

SABLE - Simple Access to Building Lifecycle Exchange www.blis-project.org/ sable 